\title{
Parasitoid wasp diversity in apple orchards along a pest management gradient
}

by

Stacy G. Mates

\author{
A thesis submitted \\ in partial fulfillment of the requirements \\ for the degree of \\ Master of Science \\ ( Natural Resources and Environment) \\ in the University of Michigan \\ December 2010
}

Thesis Committee:

Professor Ivette Perfecto, Chair

Assistant Professor Catherine Badgley

Professor Mark Hunter 



\section{ABSTRACT}

Various studies have found higher biodiversity, particularly of arthropod natural enemies, on organic than on conventional farms. However, using broad management categories to compare farm diversity is complicated by farms using intermediate practices such as Integrated Pest Management (IPM). We used a pest-management toxicity index to compare Hymenopteran parasitoid species richness, abundance, and community composition in six apple orchards in southeastern Michigan, USA, along a gradient of management practices: organic, varying levels of IPM, and conventional.

We conducted monthly vacuum-sampling of wasps in each orchard during 2009, and quantified pest-management practices based on pesticide application records. We then assigned a toxicity score to each orchard using a modified pesticide toxicity index and arranged the orchards along a toxicity gradient.

One conventional orchard had a lower toxicity score than two orchards using IPM. Additionally, toxicity scores varied from month to month within each orchard. We found higher total wasp species richness in the organic orchard; however, richness varied by month and in August a conventional orchard had the highest species richness. Total wasp abundance was highest in orchards at opposite ends of the toxicity gradient, but patterns of wasp abundance also varied by month and the conventional orchard had the highest mean abundance in August. Monthly toxicity scores did not correlate with wasp species richness, but did with wasp abundance.

Broad pest management categories were not consistent predictors of monthly variation in parasitoid wasp diversity. In contrast, monthly toxicity scores helped explain patterns of wasp abundance, though not species richness. With further refinement, a pest-management index could improve our understanding of monthly variation in orchard natural enemy biodiversity, and serve as a tool for farmers looking to increase biological control of orchard pests by parasitoid wasps. 


\section{ACKNOWLEDGEMENTS}

Thanks to my co-advisors, Ivette Perfecto and Catherine Badgley for their support throughout the thesis process, and to committee member Mark Hunter for his helpful comments on this manuscript. I'm grateful to Kathy Welch at the Center for Statistical Consultation and Research (CSCAR) for invaluable statistical advice, Mark O’Brien, Dennis Haines, Michael Sharkey and Richard Vernier for help with wasp identification, John Wise for advice on wasp sampling methods, and David Epstein and Jeanette Yanklin for recommending apple growers with whom to work. Thanks also to Katie Julian, a fantastic field assistant - I truly could have not have completed my field work without her strong arms, great ideas, and ongoing enthusiasm. Finally, a huge thank you to the apple growers who invited me into their orchards and took the time to introduce me to the complex and fascinating world of orchard management: Bill Erwin, Damon and Owen Glei, Jim Koan, Janis and Howard Miller, Scott Robertello, and Bruce Upston.

Funding for this research was provided by the Margaret Dow Towsley Scholarship, the Matthaei Botanical Gardens and Nichols Arboretum Research Endowment Fund, the University of Michigan Rackham Graduate Student Research Grant, and the University of Michigan School of Natural Resources and Environment Thesis Grant. 


\section{TABLE OF ConTENTS}

Abstract ii

Acknowledgements iii

Table of contents iv

$\begin{array}{ll}\text { Introduction } & 1\end{array}$

Methods 5

$\begin{array}{ll}\text { Results } & 11\end{array}$

$\begin{array}{ll}\text { Discussion } & 15\end{array}$

Tables

Table 1: Participating orchards 23

Table 2: Pesticide use 24

Table 3: Toxicity and species richness analysis 25

Table 4: Toxicity and abundance analysis $\quad 26$

Figures

Figure 1: IOBC toxicity scores and gradient 27

Figure 2: Total and monthly wasp species richness $\quad 28$

Figure 3: Total and monthly wasp abundance 29

Figure 4: IOBC toxicity scores vs. species richness $\quad 30$

Figure 5: IOBC toxicity scores vs. abundance 31

Figure 6: Wasp morphospecies composition 32

Figure 7: Bray-Curtis cluster analysis 33

Figure 8: Wasp family composition 34

Literature cited $\quad 35$

Appendix

Table A1: Wasp morphospecies collected 41

Table A2: Abundance analysis, pairwise comparisons 46

Figure A1: Map of participating orchards $\quad 50$ 


\section{INTRODUCTION}

A number of studies have determined that organic farms support higher biodiversity than conventional ones, whether diversity is expressed as abundance and species richness (Hole et al. 2005, Koss et al. 2005, Bengtsson et al. 2007, Letourneau and Bothwell 2008), as food-web network structure (Macfadyen et al. 2009), or as species evenness (Crowder et al. 2010). Arthropod natural enemies in particular appear to respond favorably to organic agroecosystems. In recent studies, predatory insects were on average $49 \%$ more abundant and had $84 \%$ higher species richness (Bengtsson et al. 2007), and parasitoid wasps were $87 \%$ more abundant (Letourneau and Bothwell 2008) and had significantly higher species richness (Macfadyen et al. 2009) on organic than on conventional farms.

When comparing farms, researchers face an interesting challenge: how should they decide which farms are categorized as organic or conventional? Although defined regulatory standards for organic certification exist in many countries (for an example, see the USDA National Organic Program website: http://www.ams.usda.gov/AMSv1.0/nop), studies acknowledge that "organic" and "conventional" are not simple dichotomous categories (Hole et al. 2005, Bengtsson et al. 2007, Letourneau and Bothwell 2008). For instance, practices typical of organic farms - such as avoiding synthetic pesticides and preserving mixed farming systems are also used on some conventional farms (Hole et al. 2005). Similarly, farmers interested in ecologically-friendly practices may support higher farm biodiversity regardless of how their farms are categorized (Hole et al. 2005).

Categorizing farms based on pest-management strategies is further complicated by farmer adoption of Integrated Pest Management (IPM), a set of practices that aim to maintain pest damage below economically damaging thresholds while minimizing environmental and health 
impacts from pesticides (Prokopy 1994). Comparison studies have explicitly lumped farms using IPM with conventional growers (Hole et al. 2005), eliminated them from the comparison (Bengtsson et al. 2007, Crowder et al. 2010), or not specified how these farms were categorized (Letourneau and Bothwell 2008, Macfadyen et al. 2009). Other studies treat IPM as its own management category. Koss et al. (2005) compared predator densities among three categories of potato farms: "Hard" or conventional farms with season-long use of broad-spectrum organophosphate and carbamate insecticides, "Soft" or IPM farms using mostly selective insecticides, and certified organic farms. However, pest management still varied within each of these categories: some IPM farms applied broad-spectrum pesticides at planting time, and some organic farms used pyrethrum, a broad-spectrum botanical insecticide highly toxic to beneficial arthropods (Franz et al. 1980, Koss et al. 2005).

An alternative to classifying pest-management practices into broad categories is to quantify and compare specific management practices. The International Organization for Biological Control of Noxious Animals and Plants- Pesticides and Beneficial Organisms Working Group (IOBC), a global organization that promotes environmentally safe pest control, has developed a set of standardized laboratory and semi-field tests to quantify acute pesticide toxicity to beneficial organisms (Hassan et al. 1983, 1987, 1988, 1994, Sterk et al. 1999, public communication: IOBC pesticide toxicity database accessed July 20, 2010 from http://www.iobcwprs.org/ip_ipm/03022_IOBC_PesticideDatabase_2005.pdf). Using IOBC data, Thomson and Hoffman (2006) created a toxicity metric for vineyards based on the IOBC toxicity class assigned to each pesticide and the total number of times a particular product was applied in each vineyard. Using this metric, they compared beneficial arthropod biodiversity among vineyards in the context of the cumulative effect of pesticides applied over the growing season (Thomson and 
Hoffman 2006, 2007).

Apple orchards provide a useful study system in which to compare the effects of pestmanagement strategies on beneficial arthropod diversity. Due to intensive production methods and minimal market tolerance for damaged fruit, conventional apple growers have relied on frequent applications of broad spectrum pesticides, especially organophosphates, to control arthropod pests (Perry et al. 1996, Lacey and Unruh 2005, Jones et al. 2009). In 1996, Michigan apple growers applied up to eight different fungicides and 10 different insecticides at weekly intervals, resulting in up to 15 pesticide applications during the growing season (Perry et al. 1996). Motivated by government regulations restricting organophosphate use, the development of pest resistance to common orchard pesticides, increasing pesticide costs, and public concern over pesticide exposure, apple growers and agricultural agencies are increasingly interested in adopting IPM practices to reduce pesticide use and increase biological control of major orchard pests (Prokopy et al. 1996, Gut and Brunner 1998, Suckling et al. 1999, Jones et al. 2009). IPM programs are also popular due to their demonstrated success at controlling spider mites (Acari: Tetranychidae), prominent apple foliage pests, via conservation biological control (Agnello et al. 2002, Jones et al. 2009). Biodiversity studies in apple orchards have generally included IPM orchards in their comparisons, with a range of conclusions as to where IPM practices fit within the organic versus conventional dichotomy (Suckling et al. 1999, Simon et al. 2007, Markó et al. 2009).

Parasitic Hymenoptera are common orchard natural enemies that parasitize key apple pests including codling moth, Cydia pomonella (MacPhee and Sanford 1954, Lacey and Unruh 2005), various species of leafroller and leafminer moths (Biddinger et al. 1994, Hull et al. 1997, Cross et al. 1999, Wilkinson et al. 2004), oriental fruit moth, Grapholita molesta (Atanassov et 
al. 2003) and rosy apple aphid, Dysaphis plantaginea (Cross et al. 1999, Brown and Matthews 2007). In addition to being a potential source of biological control of these orchard pests (Van Driesche and Taub 1983, Hull et al. 1997, Jones et al. 2009), parasitoid wasps are also highly sensitive to pesticides, including fungicides (Hassan et al. 1987, 1988, 1994, Thomson and Hoffman 2006) and many insecticides less harmful to other beneficial arthropods (Suckling et al. 1996, Sarvary et al. 2006, Thomson and Hoffman 2006). Therefore, parasitoid wasp diversity could serve as an indicator of both overall orchard toxicity and the potential for increased biological control upon reducing pesticide use.

We examined parasitoid wasp species richness, abundance, and community composition from May through August 2009 in six apple orchards in southeastern Michigan, USA, utilizing a range of pest-management strategies: organic, conventional, and varying levels of IPM. We determined a toxicity gradient for the six orchards using a modified version of the IOBC toxicity metric developed by Thomson and Hoffman (2006), and then compared wasp biodiversity along that gradient. Our investigation centered on two main questions. First, how would monthly patterns of parasitoid wasp species richness and abundance along a pesticide toxicity gradient compare to an overall seasonal "snapshot"? Second, where would IPM practices fit within biodiversity comparisons based on pest management - as a subset of conventional practices, or as their own, intermediate category? 


\section{METHODS}

\section{Orchard study sites}

Sampling took place at six apple orchards in southeastern Michigan, located between $43.02^{\circ}$ to $41.77^{\circ}$ north to south and $083.62^{\circ}$ to $084.60^{\circ}$ east to west (Appendix Fig. A1). The orchards represent a range of sizes, tree ages and pest management practices as summarized by the growers (Table 1). Org is a certified organic orchard using USDA National Organic Standards-approved pesticides and non-pesticidal practices, including pheromone mating disruption. ABO uses advanced IPM practices that the owner considers "all but organic," including pheromone mating disruption and a focus on building predator populations. IPM-d is an IPM orchard with diverse plantings of tree and soft fruits and vegetables, whose owner takes a "wait and see" attitude to pest control. IPM-i is a large, intensively managed orchard that uses IPM practices to control spider mites. Conv-d is an older, conventional orchard with diverse plantings of tree and small fruits. Finally, Conv is a conventional orchard that follows a set spray schedule.

Some orchards have multiple planting locations and intersperse blocks of apple trees with other crops; therefore, rather than record overall orchard size, we calculated orchard block size based on the number of hectares occupied continuously by apple trees and bordered by hedgerows, other crops, or significant roads. Orchard block sizes varied from 1.6 to 22.3 hectares (Table 1). We established a study plot within each orchard at least $17.7 \mathrm{~m}$ from any block edge, consisting of 10 Red Delicious apple trees divided into two adjacent rows of five trees each. The exception was Conv, which had only one row of Red Delicious containing all 10 sample trees. Groundcover in all orchards consisted mostly of grass mixed with small amounts of Trifolium spp., Taraxacum officinale, Daucus carota, Plantago spp. and other common weedy species; 
mowing practices varied by orchard.

\section{Orchard pesticide use and IOBC toxicity index}

We collected 2009 pesticide application records from each orchard, and conducted a onehour interview with each grower to clarify spray records and assess cultural pest control practices, pest-management philosophy, and attitudes toward orchard natural enemies (Table 2). Because of difficulty interpreting some spray records, we assumed that all pesticides were applied at the industry-recommended spray rate unless specifically noted by the grower and clarified in Table 2.

To determine an IOBC toxicity class for each pesticide, we used the on-line database of pesticide toxicity to beneficial arthropods maintained by the IOBC (public communication: IOBC pesticide toxicity database accessed July 20, 2010 from http://www.iobcwprs.org/ip_ipm/03022_IOBC_PesticideDatabase_2005.pdf). This database divides toxicity into three classes: harmless/slightly harmful ( $0-30 \%$ mortality in lab tests), moderately harmful (31-79\% mortality), and harmful ( $>80 \%$ mortality). IOBC wasp mortality data were based on Trichogramma cacoeciae, which the IOBC used as an indicator species, except for the insecticide thiacloprid, for which the IOBC only evaluated effects on Aphidius rhopalosiphi. Using a modified version of the method developed by Thomson and Hoffman (2006), which based the index on a four-class system, we assigned a toxicity class to each pesticide on a scale of $0-2$ from the lowest to the highest mortality class. By assigning a zero value to pesticides causing less than $30 \%$ mortality, we effectively eliminated these pesticides from each orchard's toxicity calculation (Thomson and Hoffman 2006). For pesticides not included in the IOBC database, we found studies that evaluated toxicity to parasitoid wasps, giving preference to studies that followed IOBC testing procedures (Table 2). We calculated total IOBC toxicity 
scores for each orchard by multiplying each pesticide's IOBC toxicity class by the number of times that pesticide was applied from the start of the season through our August sample date, and then summing pesticide toxicity scores. We also calculated monthly IOBC toxicity scores, using the time between sample dates to represent each month (Fig. 1a).

The orchards also utilized cultural or physical pest-management practices which were not included in their spray records (Table 2). Org used pheromone mating disruption to control codling moth (C. pomonella), while ABO used mating disruption to control both codling moth and oriental fruit moth (G. molesta). IPM-i delayed spring mowing of the orchard floor to allow predatory mites to migrate from overwintering sites up into the apple trees, and Org limited mowing to preserve weeds that could serve as alternative pollen and nectar sources for predatory arthropods. Finally, all six orchards utilized some form of scouting and trapping in 2009 to monitor pest populations. Org and ABO routinely contract with a professional orchard scout who visited each orchard weekly, IPM-i employs a scout as part of regular orchard staff, and IPM-d, Conv-d, and Conv all utilized a scout in 2009 provided gratis by a local pesticide company, Wilbur-Ellis.

\section{Parasitoid sampling and identification}

Sampling took place once per month at each orchard from May through August 2009:

May 14-21, June 17-26, July 21-30, and August 16-21. We used a modified leaf blower/vacuum with fine $(\leq 30 \mu \mathrm{m})$ mesh bags fitted into the tube to vacuum-sample arthropods for one minute from the mid and lower canopy of each of the 10 apple trees. Vacuum-sampling allows for a more complete sample of flying arthropods than the traditional collection method of branch beating (Harper and Guynn 1998, J. Wise, personal communication). We placed the mesh sampling bags into sealable plastic bags with a cotton pad soaked in $99.5 \%$ ethyl acetate, and 
stored the bags in a chilled cooler in the field. In the lab, we separated parasitic Hymenoptera from other arthropods and debris, then stored the wasps in the freezer and other specimens in $70 \%$ ethyl alcohol. Once identified, wasps were stored in 95\% ethyl alcohol.

We identified Hymenoptera collected from June through August to family (Borror and White 1970, Borror et al. 1989, Grissell and Schauff 1990) and morphospecies, following family and subfamily taxonomy of the Hymenoptera Online Database maintained by Norman et al. (public communication: accessed January 11, 2010 from http://hol.osu.edu/). Voucher specimens were stored in the laboratory of I. Perfecto at the University of Michigan. Wasps from May samples were difficult to identify to morphospecies due to immediate storage in alcohol; therefore, May wasps were counted for abundance comparisons only.

\section{Data Analysis}

We used Estimate S software (Colwell 2006) to calculate parasitoid wasp smooth species accumulation curves and compare total and monthly species richness among orchards. We then examined the relationship between monthly IOBC scores and monthly species richness counts for each orchard, using a generalized linear mixed model (GLMM) to account for multiple measurements over time for each orchard (Molenberghs and Verbeke 2005). Species richness was treated as the total count of species collected across all trees within a given orchard and month, and thus analyzed at the orchard level. Since species richness was count data which did not meet the assumptions necessary for a Poisson distribution (mean equal to variance), we specified a negative binomial distribution. To account for between-orchard variability, we included random coefficients for the intercept and slope of IOBC toxicity scores within each orchard.

We also used the model above to examine the relationship between species richness and 
two potential confounding factors: orchard block size, which could affect species richness by altering immigration and recolonization potential, and tree age, since older trees have been shown to support greater arthropod diversity (Brown and Schmitt 2001). Additionally, because pest-management practices and wasp and prey/host life-cycles varied across months, we also examined the relationship between IOBC toxicity scores and species richness within each month using a negative binomial regression (generalized linear model). As we had only one aggregated species count per orchard within each month, we did not include a random effect in the analysis for individual months. Generalized linear models for the entire season were analyzed using SAS Release 9.2 (SAS Institute, Cary, North Carolina, USA), while relationships within individual months were analyzed using SPSS Versions 17.0 and 18.0 (IPM Software, Chicago, Illinois, USA).

To evaluate the effects of individual orchard practices on monthly parasitoid wasp abundance, we used repeated-measures ANOVA with orchard, month, and the interaction of orchard by month as fixed effects. Since the subject of our model was the individual tree measured over time in each orchard, we used a compound-symmetric covariance structure to account for repeated measurements and thus non-independent residuals for the same tree over time. The interaction of orchard by month was significant, indicating that orchard to orchard differences varied by month; therefore, we performed post-hoc tests to compare mean wasp abundance across orchards within each month. A Bonferroni correction for multiple comparisons was used for the post-hoc tests within each month. Abundance data was natural log transformed for all abundance analyses to obtain more normally distributed residuals.

We then analyzed the relationship between monthly IOBC toxicity scores and wasp abundance using a linear mixed model (LMM) (Molenberghs and Verbeke 2000). As our subject 
was the individual tree measured repeatedly over time, we used a compound-symmetric covariance structure to account for correlations within each tree. We allowed orchard to be a random effect because we focused this analysis on IOBC toxicity rather than individual orchard practices. Abundance was natural log transformed to improve normality. Using the same linear mixed model, we examined orchard block size and tree age as potential confounding factors for abundance. Linear mixed models were calculated using SPSS Versions 17.0 and 18.0 (IPM Software, Chicago, Illinois, USA).

Since orchard owners set their spray schedules independently of our study, we acknowledged that the last pesticide application before each sample date could confound the relationship between overall monthly IOBC scores and wasp diversity. Therefore, we calculated a "last spray" toxicity ratio for each month by dividing the IOBC toxicity rating of the most recent pesticide application by number of days elapsed between application and our sample date, assuming that the intensity of impact would decrease over time. If an orchard applied a mixture of pesticides on the same date, we summed the IOBC toxicity class of each individual pesticide for a total IOBC rating for the last spray. We then used the models discussed above to examine the relationship between the last spray ratio and wasp species richness or abundance, including total monthly IOBC toxicity scores as a covariate.

To compare wasp community composition among orchards, we tallied the number of individuals per species and family collected at each orchard, then used a paired-group cluster analysis in PAST Version 2.02 (Hammer et al. 2001) based on the Bray-Curtis dissimilarity index (Bray and Curtis 1957) to group orchards based on similar morphospecies. 


\section{RESULTS}

\section{IOBC toxicity index for orchards}

Based on grower reporting, we hypothesized that the orchards' pest management practices would rank as follows from least to most toxic to parasitoid wasps: Org, ABO, IPM-d, IPM-i, Conv-d, and Conv. The total IOBC toxicity score for each orchard supported this gradient with one exception: Conv-d had a lower IOBC toxicity score than either IPM-d or IPM-i. The final gradient - Org, ABO, Conv-d, IPM-d = IPM-i, and Conv - reflected total IOBC toxicity scores from 19 to 29 (Table 2, Fig. 1b).

IOBC toxicity scores also varied by month (Fig. 1a). Although we saw a general trend of decreasing toxicity from May to August, toxicity scores at three orchards (ABO, IPM-d, and Conv) actually peaked in June. IPM-i had a May IOBC toxicity score of 20, the highest score at any orchard during any month, but had June and July scores which were the lowest for those months. Finally, two orchards, ABO, and Conv, did not apply any pesticides between our July and August sampling dates and thus had August IOBC toxicity scores of zero.

\section{Wasp species richness and abundance}

During May through August 2009 at the six orchards, we collected 892 parasitoid wasps, 811 of which we identified to 169 morphospecies in 16 families (Appendix Table A1). The dominant families were Aphelinidae, with six species and 280 individuals, and Eulophidae, with 35 species and 262 individuals. A few abundant morphospecies within these two families accounted for the overall family dominance: morphospecies Aphel_04 was represented by 260 individuals, and Eulop_08, Eulop_09, and Eulop_19 were represented by 93, 55, and 24 individuals, respectively. We also collected 96 morphospecies in various families that were represented by a single individual (singletons). 
Species accumulation curves for June-August 2009 totals indicated significantly higher total wasp species richness at Org than at the other five orchards (Fig. 2a). However, patterns of species richness varied from month to month (Fig. 2b) and only the species accumulation pattern for July matched that of total species richness. Most notably, wasp species richness at Conv was zero in June, but rose to the highest richness of the six orchards in August with 30 species. Org had the highest species richness in June and July, but dropped in August to second highest after Conv.

Patterns of wasp abundance also varied from month to month. May-August totals showed similar mean wasp abundance per tree at Org, ABO and Conv (Fig. 3a). However, when we examined monthly variation in mean wasp abundance, we found different orchard to orchard differences depending on the month (Table A2) and distinct patterns at individual orchards over the season (Table 4, Fig. 3b). Abundance at Conv followed a pattern similar to species richness: we collected few to no wasps from May through July, but saw a dramatic spike in August to 18 wasps per tree, the highest mean wasp abundance found at any orchard during the 2009 season. Abundance at Org also followed the same pattern as species richness; Org had the highest abundance from May through July, but then dropped in August. At ABO, abundance increased steadily over the season, while at IPM-d, abundance peaked in July and then dropped in August. Finally, abundance at Conv-d and IPM-i remained low throughout the season.

\section{Relationship between IOBC toxicity scores and wasp diversity}

Wasp species richness from June-August was unaffected by orchards' monthly IOBC toxicity scores (Table 3, Fig. 4, p = 0.525). When we examined the relationship between species richness and monthly IOBC toxicity scores at individual orchards, we did not find any significant relationships (Table 3). There was a negative trend in the relationship between species richness 
and monthly IOBC scores at Conv, but flat relationships at ABO, IPM-d, and IPM-i, and positive relationships at Org and Conv-d, albeit over a narrow three-point range of IOBC scores (Fig. 4). Examining the relationship between toxicity scores and species richness within specific months, we found negative but non-significant relationships between each month's IOBC toxicity scores and species richness (Table 3; June $p=0.565$, July $p=0.714$, August $p=0.720$ ). Likewise, neither orchard block size $(p=0.598)$ nor tree age $(p=0.254)$ had a significant impact on species richness (Table 3).

In contrast, wasp abundance from May-August showed a significant negative relationship with monthly IOBC toxicity scores in a mixed linear model (Table 4, Fig. $5, \mathrm{p}=0.014$ ). While wasp abundance was variable at lower IOBC toxicity scores, few to no wasps were found at monthly IOBC toxicity scores of 13 or greater. Neither orchard block size $(\mathrm{p}=0.525)$ nor tree age $(p=0.932)$ had a significant effect on abundance when we controlled for IOBC toxicity scores, nor influenced the significant relationship between IOBC and abundance (Table 4).

The last spray toxicity ratio (the most recent spray's cumulative IOBC class divided by the number of days between application and sample date) had a significant negative relationship with abundance (Table 4, $p=0.031$ ), but that relationship disappeared if we controlled for monthly IOBC toxicity scores (Table $4, p=0.350$ ). Species richness was unaffected by the last spray ratio (Table $3, \mathrm{p}=0.128)$.

\section{Community composition}

We compared morphospecies composition at the six orchards in terms of total number of individuals per species from June through August (Fig. 6). Singletons were common at all orchards, ranging from $14 \%$ of the total individuals at $\mathrm{ABO}$ and Conv to $81 \%$ at IPM-i. Additionally, at every orchard except IPM-i, we collected a dominant species accounting for 
27\% (Org) to 65\% (IPM-d) of total individuals. The aphelinid Aphel_04 was found at all orchards except Org, and was the dominant species at ABO (61\%), Conv-d (29\%), and IPM-d (65\%). In contrast, the dominant species at Org and Conv were both eulophids: Eulop_09 at Org (27\%) and Eulop_08 at Conv (47\%). Cluster analysis based on Bray-Curtis dissimilarity indices (Fig. 7) showed that ABO and IPM-d had the most similar species composition (Bray-Curtis = 0.559), based in large part on Aphel_04's dominance at both orchards. Org was the least similar to any other orchard, with a maximum Bray-Curtis value of 0.108 with Conv.

Family composition varied among orchards in parallel with species composition, with Aphelinidae well represented at all orchards except Org and IPM-i, and Eulophidae the dominant family at Org and Conv (Fig. 8). The number of families ranged from nine at Conv to 13 at $\mathrm{ABO}$, and even orchards with low abundance showed moderate family diversity, with 10 families at IPM-i and 11 at Conv-d. 


\section{Discussion}

In this study, we compared parasitoid wasp diversity in six apple orchards along a gradient of pest-management intensity. We found that broad pest-management categories organic, IPM, and conventional - were inconsistent predictors of parasitoid wasp diversity, especially when we took into account monthly variation in species richness and abundance. However, using monthly and seasonal IOBC toxicity scores as an index of pest-management intensity (Thomson and Hoffman 2006) allowed us to better understand how orchard pest management can affect biodiversity.

\section{Diversity and IOBC toxicity scores}

Although other biodiversity comparison studies (Hole et al. 2005, Koss et al. 2005, Bengtsson et al. 2007, Letourneau and Bothwell 2008, Macfadyen et al. 2009, Crowder et al. 2010) reported seasonal or yearly totals of diversity, our results indicated that examining monthly changes in species richness and abundance can give a more informative picture of how diversity varies with pest-management practices over the season. In terms of species richness, our season totals supported the results of previous studies (Hole et al. 2005, Bengtsson et al. 2007, Letourneau and Bothwell 2008) by finding significantly higher diversity in the organic orchard than in all other orchards, and suggested that IPM and conventional practices support similar numbers of species and could thus be pooled together (Fig. 2a). However, upon examining patterns in individual months, only the July pattern matched that of season totals (Fig. $2 b)$. In June, species richness followed a gradual gradient which aligned with the overall IOBC toxicity gradient $(\mathrm{Org}-\mathrm{ABO}-\mathrm{Conv}-\mathrm{d}-\mathrm{IPM}-\mathrm{d}-\mathrm{IPM}-\mathrm{i}-\mathrm{Conv})$, suggesting instead that intermediate pesticide intensity permitted intermediate species richness as found by Suckling et al. (1999). August also followed a gradual gradient, but this time with the highest species 
richness in the most "conventional" orchard, Conv, in direct contrast to the conclusions of most previous studies (Hole et al. 2005, Koss et al. 2005, Bengtsson et al. 2007, Letourneau and Bothwell 2008; for an exception see Simon et al. 2007).

Season totals for abundance also appeared to contradict the results of previous biodiversity comparisons, since we found the highest mean wasp abundance in the organic (Org), "all but organic" ( $\mathrm{ABO}$ ) and conventional (Conv) orchards, even though these orchards fell at opposite ends of the IOBC toxicity gradient (Fig. 3a). Monthly wasp abundance showed a more complex picture, with individual patterns of change in abundance at each orchard (Fig. 3b). Most notably, $86 \%$ of the wasps found at Conv were collected in August, with no wasps at all in June and fewer than two wasps per tree in May and July.

Monthly IOBC toxicity scores help explain some of this variation in diversity from month to month. First, pesticide toxicity levels appeared to create an upper bound on wasp abundance, with variation at lower IOBC toxicity scores but few to no wasps at the highest toxicity scores (Fig. 5). This relationship is also reflected by examining seasonal trends in IOBC toxicity scores (Fig. 1a) and abundance (Fig. 3b): as toxicity scores generally decreased over the season, the upper limit of abundance increased. The last pesticide application before each sample date, expressed as a last spray ratio, did have a significant effect on abundance, but that effect disappeared once we considered the month's overall IOBC toxicity score (Table 4).

The relationship between monthly IOBC toxicity scores and species richness was less clear cut. A general trend of decreasing IOBC toxicity scores over the season (Fig. 1a) coincided with an increase in the minimum number of species found at any orchard (Fig. 2b), suggesting that toxicity could set the bottom range of species richness; however, this relationship was not significant when analyzed at either the seasonal or monthly level (Table 3, Fig. 4). These results 
suggest that while pesticide toxicity set an upper limit on how many wasps could survive in each orchard, the species richness of these wasps was likely shaped by other factors, such as host presence and life cycles (Brown 1993, Holzschuh et al. 2010) or diversity of alternative hosts and adult food sources within and surrounding the orchard (Lacey and Unruh 2005, Bianchi et al. 2006, Brown and Matthews 2007). The last pesticide application before spray date did not have a significant effect on species richness (Table 3).

Hymenopteran community structure can be shaped in part by pest management, since pesticides have varying effects on different species and families (Simon et al. 2007). Org appeared to have a distinctly different wasp community that did the other orchards, according to Bray-Curtis dissimilarity indices (Fig. 7) and the lack of Aphel_04, which was present at the other five orchards and the dominant species at three of the five. Also notable was the high percentage of singletons found at all orchards, regardless of pest-management strategy. Rarity may be typical of parasitic Hymenoptera, which have been found to serve in natural systems in low numbers but high species richness and can perform important regulatory functions despite small population size (LaSalle 1993).

\section{Diversity patterns in specific orchards}

A few individual orchards went through notable changes in species richness or abundance over the season. First, the dramatic August increase in wasp abundance and species richness at Conv can be partly explained by monthly IOBC toxicity scores, since Conv had an August toxicity score of zero. Since Conv is a relatively small orchard close to a small creek surrounded by brushy habitat, wasps were likely able to immigrate into the study area from extra-orchard areas once spraying ceased (Brown 1993, Miliczky and Horton 2005, Markó et al. 2009). ABO also had an August toxicity score of zero and a corresponding increase in wasp abundance from 
July to August. The increase at $\mathrm{ABO}$ may have been less dramatic than at Conv because of the greater distance to extra-orchard habitat (Miliczky and Horton 2005), or because the higher baseline wasp population at $\mathrm{ABO}$ already represented a greater proportion of regional wasp diversity (Hooper et al. 2005).

Org also stood out due to higher wasp diversity during June and July than might be predicted based on its monthly toxicity scores. One possible reason that Org was a positive outlier was that IOBC toxicity scores overestimated the actual toxicity of the pesticides used. For example, while the IOBC classed sulfur as "highly toxic" based on mortality of its indicator species Trichogramma cacoeciae, even high concentrations of sulfur caused only moderate mortality of Aphidius rhopalosiphi (public communication: IOBC pesticide toxicity database accessed July 20, 2010 from http://www.iobc-wprs.org/ip_ipm/03022_IOBC_

PesticideDatabase_2005.pdf). Therefore, if sulfur were less toxic to the wasp species present at Org than to T. cacoeciae, then Org's June IOBC toxicity score might have been exaggerated. Alternately, other practices at Org might have helped increase diversity regardless of pesticide application, such as grower tolerance of foliage pests which could serve as alternative hosts, or reduced mowing to preserve weeds acting as pollen and nectar sources for adult wasps (J. Koan, personal communication).

We were also intrigued by the combination of low wasp abundance with relatively high species richness found at IPM-i and Conv-d, where singletons accounted for $81 \%$ and $36 \%$ of the number of wasps, respectively. This pattern may have been a reflection of parasitic wasps' characteristic rarity (LaSalle 1993), but at IPM-i could also reflect a combination of orchard size and high pesticide use. IPM-i was the largest orchard in our study, with no obvious potential refugia within sight of the study block, and had a May IOBC toxicity score that was the highest 
score at any orchard during any month. We only collected one wasp in May, indicating a low baseline resident population. Therefore, even though IPM-i had low toxicity scores over the rest of the season, if wasps were unable to migrate easily into the orchard because of greater distance to extra-orchard habitat (Miliczky and Horton 2005, Bianchi et al. 2006), the few wasps found were likely "foragers" passing through but not yet established or actively parasitizing (Brown and Schmitt 2001). In contrast, Conv-d had the third lowest IOBC toxicity index of the six orchards, and is a small orchard with blocks of apples interplanted with diverse crops including peaches, which could serve as attractive alternative nectar sources for parasitoid wasps (Brown and Schmitt 2001). Therefore, the low wasp abundance at Conv-d was not well explained by our study, and may be due to historical pesticide use or other practices not captured in 2009 records.

\section{Orchard size and diversity}

Although orchard block size did not show a significant relationship with abundance or species richness in our statistical analyses (Table 3, Table 4), distance to extra-orchard habitat has been shown to influence parasitoid diversity and activity (Altieri and Schmidt 1986, Miliczky and Horton 2005, Bianchi et al. 2006) and helps explain some of the monthly variation in diversity, especially at Conv and IPM-i. It is likely that our small sample size and the confounding effects of toxicity levels and orchard block size limited the effectiveness of the statistical test for block size; we only examined one orchard with a very large block size (IPM-i) and the two orchards of intermediate block size coincidentally had the lowest IOBC toxicity scores (Org and $\mathrm{ABO})$. For future studies, rather than use orchard block size as a surrogate for distance to extra-orchard habitat, it would be useful to measure specific distances from study sites to potential areas likely to support parasitoids.

\section{Limitations of IOBC toxicity index}


Although using cumulative IOBC toxicity scores as a pest management index allowed for a more complete explanation of parasitic Hymenoptera diversity differences among the six orchards than using broad management categories, the index did not adequately explain species richness or patterns at orchards like Conv-d. Many factors in addition to pest management can influence natural enemy diversity, including plant and prey/host diversity within the orchard (Brown 1993, Brown and Schmitt 2001, Holzschuh et al. 2010), prey/host population cycles (Brown 1993, Thomson and Hoffman 2007), availability of alternative prey/hosts and food sources (Landis et al. 2000, Lacey and Unruh 2005, Bianchi et al. 2006), potential for predator recolonization after disturbance (Miliczky and Horton 2005, Markó et al. 2009) and regional landscape complexity (Bianchi et al. 2006, Tscharntke et al. 2008). These factors may also interact; for instance, Holzschuh et al. (2010) pointed out that while bee diversity generally decreased with reduced landscape complexity around agricultural fields, this effect did not occur on organic farms.

Additionally, the IOBC toxicity index is based on a set of assumptions that may not adequately account for the complex ways pesticides could impact parasitoid wasps. First, by summing the cumulative scores for each pesticide used at an orchard, we treated the effects of different pesticides as additive. If instead some pesticides interact synergistically, then the IOBC toxicity index could underestimate the actual cumulative impact on wasps (Thomson and Hoffman 2007). Second, IOBC toxicity classes for individual pesticides are based on acute toxicity; however, since pesticides have varying persistence, two pesticides with comparable acute toxicity could have different impacts over time (Williams et al. 2003). Third, by focusing only on direct mortality, IOBC toxicity classes do not account for sublethal effects of pesticides that could also affect parasitoid abundance and species richness, but are more difficult to 
quantify (Thomson and Hoffman 2007, Jones et al. 2009). Fourth, IOBC toxicity classes are based on indicator species, which facilitates consistent pesticide comparisons, but may not account for the actual impact on local species, especially in field settings (Thomson and Hoffman 2007). Finally, timing of application could affect impact, since immature life stages of the parasitoid are enclosed in their hosts and therefore may be partially protected from pesticides (Longley 1999, Bastos et al. 2006).

Based on these limitations, Thomson and Hoffman (2007) proposed a refined pesticide impact metric based on three variables: the relative reduction of the predator population via either lethal or sublethal effects; the persistence time of each pesticide; and the potential for the predator to re-populate the agroecosystem from surrounding areas. Although these variables could be challenging to calculate based on available pesticide data, they could also help create a pest-management index that allows for more meaningful comparisons of different systems. Additionally, it would be ideal to carry out multi-year diversity comparisons between different farms to tease out longer term patterns of variation in abundance and species richness.

\section{Conclusions and management implications}

Our study points to some possible implications for apple growers and researchers interested in further reducing pesticide use in order to encourage natural enemy diversity. While parasitoid wasps have been shown to provide only partial biological control of apple foliar and fruit pests (Van Driesche and Taub 1983, Hull et al. 1997, Jones et al. 2009), they could serve as an important tool in combination with non-pesticidal management strategies such as pheromone mating disruption for C. pomonella. Therefore, parasitoid wasps represent a relatively untapped area of focus for orchard IPM extension.

Our first major finding was that parasitoid wasp abundance and species richness in an 
orchard can vary, sometimes dramatically, from month to month. As the large August increase in wasp abundance and species richness at Conv demonstrated, wasps could recolonize even a heavily sprayed orchard after pesticide application ceased if the orchard is sufficiently close to a wasp refuge or source population. Therefore, growers could increase the potential for supplemental biological control of various pests by creating or preserving habitat favorable to wasps within or near orchards (Lacey and Unruh 2005), and by timing sprays to reduce parasitoid exposure during more vulnerable life stages (Longley 1999, Bastos et al. 2006). Additionally, further research could examine when during the season wasps make the greatest contribution toward biological control of pests, so that growers could aim to preserve wasp diversity during the time of maximum impact. For example, Cook et al. (2007) report that parasitoids can effectively control aphids only if the parasitoids enter fields before exponential aphid population growth begins.

We also found that while the IOBC toxicity index had its limits, especially in explaining variation in wasp species richness, it served as a better predictor of wasp abundance than broad orchard management categories like organic, IPM, and conventional. Apple growers and extension educators could utilize such an index to increase wasp and other natural enemy populations and thus biological control of orchard pests. For instance, current apple IPM programs to preserve beneficial arthropods do not generally focus on fungicides, yet fungicides made up $58-71 \%$ of the total pesticide applications at each of the six orchards and can be as toxic to parasitoid wasps as many insecticides are (Table 2). By using a standardized toxicity index to help growers select both insecticides and fungicides that are minimally toxic to parasitoid wasps, growers could build the populations of these currently underutilized natural enemies and complement their efforts to control apple pests with fewer and less toxic pesticides. 


\section{TABLES}

TABLE 1. Participating orchards' pest management category, block size, tree age, strain of Red Delicious apples planted, and notes on pest management practices.

\begin{tabular}{|c|c|c|c|c|c|c|}
\hline Orchard & $\begin{array}{l}\text { Pest management } \\
\text { category }\end{array}$ & $\begin{array}{l}\text { Orchard } \\
\text { block size } \\
(\text { ha })^{\text {a }}\end{array}$ & $\begin{array}{l}\text { Tree } \\
\text { age } \\
(\mathrm{yrs})\end{array}$ & $\begin{array}{c}\text { Tree } \\
\text { spacing } \\
(\mathrm{m})^{\mathrm{b}}\end{array}$ & $\begin{array}{l}\text { Red } \\
\text { Delicious } \\
\text { strain }\end{array}$ & Pest management notes \\
\hline Org & Certified organic & 7.3 & 15 & $4.4 \times 5.5$ & Red Chief & $\begin{array}{l}\text { Holistic approach, high } \\
\text { tolerance of leaf damage }\end{array}$ \\
\hline $\mathrm{ABO}$ & IPM, advanced & 8.1 & 15 & $2.6 \times 5.4$ & Cambell & $\begin{array}{l}\text { Owner calls practices "all } \\
\text { but organic" }\end{array}$ \\
\hline IPM-d & $\begin{array}{l}\text { IPM, mid-level, } \\
\text { diverse }\end{array}$ & 3.3 & 25 & $3.6 \times 5.6$ & Red Chief & $\begin{array}{l}\text { Diverse plantings of tree } \\
\text { and small fruits, vegetables; } \\
\text { "wait and see" approach to } \\
\text { pest control }\end{array}$ \\
\hline IPM-i & IPM, intensive & 22.3 & 8 & $2.1 \times 4.7$ & IT Delicious & $\begin{array}{l}\text { Intensive production, IPM } \\
\text { for mite control }\end{array}$ \\
\hline Conv-d & $\begin{array}{l}\text { Conventional, } \\
\text { diverse }\end{array}$ & 1.6 & 40 & $5.1 \times 7.0$ & Unknown & $\begin{array}{l}\text { Diverse plantings of tree } \\
\text { and small fruits }\end{array}$ \\
\hline Conv & Conventional & 4.9 & 9 & $6.2 \times 6.2$ & Adams & $\begin{array}{l}\text { Follows strict spray } \\
\text { schedule }\end{array}$ \\
\hline
\end{tabular}

Notes. ${ }^{a}$ Orchard block size based on the number of hectares occupied by apple trees and bordered by hedgerows, other crops, or significant roads. ${ }^{\mathrm{b}}$ Tree spacing $=$ distance between trees within row $\mathrm{x}$ distance between rows. Exception is Conv-d, where table reports average distance between trees because tree spacing varied from 4.1 to $8.9 \mathrm{~m}$. 
TABLE 2. Pesticide applications with IOBC toxicity classes, total orchard IOBC toxicity scores, and other pest management practices used in study orchards, January through August 2009.

\begin{tabular}{|c|c|c|c|c|c|c|c|}
\hline \multirow[b]{2}{*}{ Pesticide } & \multirow{2}{*}{$\begin{array}{l}\text { Adjusted } \\
\text { IOBC class }\end{array}$} & \multicolumn{6}{|c|}{ Applications per orchard } \\
\hline & & Org & $\mathrm{ABO}$ & Conv-d & IPM-d & IPM-i & Conv \\
\hline \multicolumn{8}{|l|}{ Fungicides / bactericides } \\
\hline Streptomycin sulfate & $0^{\mathrm{a}}$ & 0 & 0 & 0 & 1 & 1 & 2 \\
\hline Captan & 1 & 0 & 1 & 6 & 3 & 6 & 4 \\
\hline Copper hydroxide & $0^{\mathrm{b}}$ & 14 & 0 & 1 & 1 & 1 & 1 \\
\hline Dithiocarbamate/Ziram & $0^{\mathrm{c}}$ & 0 & 2 & 2 & 2 & 1 & 0 \\
\hline Fenarimol & 1 & 0 & 0 & 2 & 3 & 0 & 0 \\
\hline Kresoxim-methyl & 0 & 0 & 0 & 0 & 1 & 0 & 1 \\
\hline Lime-sulfur & 2 & 1 & 0 & 0 & 0 & 0 & 0 \\
\hline Mancozeb & $1^{\mathrm{d}}$ & 0 & 10 & 3 & 4 & 3 & 4 \\
\hline Myclobutanil & $0^{\mathrm{e}}$ & 0 & 2 & 0 & 2 & 2 & 4 \\
\hline Pyrimethanil & 2 & 0 & 0 & 1 & 0 & 0 & 1 \\
\hline Thiophanate-Methyl & 0 & 0 & 0 & 0 & 0 & 0 & 1 \\
\hline Trifloxystrobin & $0^{\mathrm{f}}$ & 0 & 0 & 0 & 1 & 1 & 1 \\
\hline Sulfur & 2 & 4 & 0 & 0 & 0 & 0 & 0 \\
\hline \multicolumn{8}{|l|}{ Insecticides / miticides } \\
\hline Acetamiprid & $2^{g}$ & 0 & 0 & 1 & 2 & 0 & 1 \\
\hline Azinphos-methyl & 2 & 0 & 0 & 0 & 0 & 3 & 3 \\
\hline Carbaryl ${ }^{\mathrm{h}}$ & 2 & 0 & 1 & 1 & 1 & 2 & 2 \\
\hline Chlorpyrifos & 2 & 0 & 0 & 0 & 0 & 1 & 0 \\
\hline C. pomonella granulosis virus & 0 & 1 & 0 & 0 & 0 & 0 & 0 \\
\hline Imidacloprid & 2 & 0 & 0 & 0 & 1 & 1 & 0 \\
\hline Imidacloprid + Cyfluthrin & $2^{f}$ & 0 & 0 & 0 & 0 & 0 & 1 \\
\hline Indoxacarb & 1 & 0 & 0 & 1 & 0 & 0 & 0 \\
\hline Novaluron & $1^{\mathrm{i}}$ & 0 & 1 & 1 & 0 & 0 & 0 \\
\hline Petroleum Oil & $1^{\mathrm{j}}$ & 8 & 1 & 1 & 0 & 1 & 1 \\
\hline Phosmet & 2 & 0 & 1 & 1 & 4 & 0 & 2 \\
\hline Pyrethrin (organic certified) & $1^{\mathrm{k}}$ & 1 & 0 & 0 & 0 & 0 & 0 \\
\hline Rynaxypyr/Chlorantraniliprole & $0^{1}$ & 0 & 0 & 2 & 0 & 0 & 0 \\
\hline Spinetoram & 1 & 0 & 0 & 1 & 0 & 0 & 0 \\
\hline Spinosad (GF 120) & 1 & 2 & 0 & 0 & 0 & 0 & 0 \\
\hline Thiacloprid & 2 & 0 & 2 & 0 & 1 & 1 & 0 \\
\hline Spirodiclofen & 0 & 0 & 0 & 1 & 1 & 0 & 0 \\
\hline Total pesticide applications & & 31 & 21 & 25 & 28 & 24 & 29 \\
\hline Total pesticides used & & 7 & 9 & 15 & 15 & 13 & 15 \\
\hline 2009 IOBC toxicity score & & 19 & 21 & 23 & 28 & 28 & 29 \\
\hline \multicolumn{8}{|l|}{ Other pest control practices } \\
\hline Pheromone mating disruption & & 1 & 1 & 0 & 0 & 0 & 0 \\
\hline Delayed mowing $^{\mathrm{m}}$ & & 1 & 0 & 0 & 0 & 1 & 0 \\
\hline Orchard scout / traps ${ }^{n}$ & & 1 & 1 & 1 & 1 & 1 & 1 \\
\hline \multicolumn{8}{|c|}{$\begin{array}{l}\text { Notes: }{ }^{\mathrm{a}} \text { U.S. EPA assessment. }{ }^{\mathrm{b}} \text { Thomson and Hoffman } 2006 .{ }^{\mathrm{c}} \text { Mani and Krishnamoorthy } 1997 .{ }^{\mathrm{d}} \text { Class } 1 \text { assigned } \\
\text { due to spray concentration. }{ }^{\mathrm{e}} \text { Manzoni et al. } 2006 .{ }^{\mathrm{f}} \text { Carmo et al. } 2010 .{ }^{\mathrm{g}} \text { Estay et al. } 2005 .{ }^{\mathrm{h}} \text { Used as apple thinning } \\
\text { agent. }{ }^{\mathrm{i}} \text { Bastos et al. } 2006 . \\
\text { not sample trees. }\end{array}$} \\
\hline
\end{tabular}


TABLE 3. Relationship between IOBC pesticide toxicity scores and counts of total parasitoid wasp species richness per orchard. Statistically significant results $(\mathrm{p}<0.05)$ are indicated by an asterisk.

\begin{tabular}{|c|c|c|c|c|}
\hline Predictor & Numerator df & Denominator df & $\mathrm{F}$ & $\mathrm{p}$ \\
\hline Monthly IOBC toxicity scores ${ }^{\text {a }}$ & 1 & 5 & 0.47 & 0.525 \\
\hline Orchard block size ${ }^{\mathrm{a}, \mathrm{b}}$ & 1 & 6 & 0.31 & 0.598 \\
\hline Tree age ${ }^{a, b}$ & 1 & 5 & 1.59 & 0.254 \\
\hline Last spray ratio a, b & 1 & 5 & 3.32 & 0.128 \\
\hline Predictor & Wald & Thi-Square & $\mathrm{df}$ & $\mathrm{p}$ \\
\hline Total IOBC toxicity scores ${ }^{c, d}$ & & 0.346 & 1 & 0.556 \\
\hline \multicolumn{5}{|c|}{ Monthly IOBC toxicity scores - by month: ${ }^{\mathrm{c}}$} \\
\hline June & & 0.331 & 1 & 0.565 \\
\hline July & & 0.134 & 1 & 0.714 \\
\hline August & & 0.129 & 1 & 0.720 \\
\hline \multicolumn{5}{|c|}{ Monthly IOBC toxicity scores - by orchard: ${ }^{c}$} \\
\hline Org & & 0.080 & 1 & 0.777 \\
\hline $\mathrm{ABO}$ & & 0.003 & 1 & 0.953 \\
\hline Conv-d & & 0.088 & 1 & 0.767 \\
\hline IPM-d & & 0.000 & 1 & 0.997 \\
\hline IPM-i & & 0.001 & 1 & 0.973 \\
\hline Conv & & 3.264 & 1 & 0.071 \\
\hline
\end{tabular}

${ }^{a}$ Statistical model: generalized linear mixed model (GLMM) with random coefficients for the intercept and slope of IOBC scores for each orchard. We specified a negative binomial distribution of species richness counts.

${ }^{\mathrm{b}}$ Monthly IOBC toxicity scores included as covariate.

${ }^{\mathrm{c}}$ Statistical model: negative binomial regression. We specified a negative binomial distribution of species richness counts.

${ }^{\mathrm{d}}$ Uses count of total species richness for the season (June-August 2009). All other analyses in this table used monthly species richness counts. 
TABLE 4. Relationship between parasitoid wasp abundance and individual orchard practices, and between abundance and IOBC toxicity scores. Statistically significant results $(p<0.05)$ are indicated by an asterisk.

\begin{tabular}{|c|c|c|c|c|}
\hline Predictor & Numerator df & Denominator df & $\mathrm{F}$ & $\mathrm{p}$ \\
\hline \multicolumn{5}{|l|}{ Monthly abundance comparisons: ${ }^{a}$} \\
\hline Month & 3 & 162 & 59.483 & $<0.001^{*}$ \\
\hline Orchard & 5 & 54 & 26.579 & $<0.001^{*}$ \\
\hline Orchard by month ${ }^{\mathrm{b}}$ & 15 & 162 & 10.712 & $<0.001 *$ \\
\hline Monthly IOBC toxicity scores ${ }^{c}$ & 1 & 6 & 12.442 & $0.014 *$ \\
\hline Orchard block size ${ }^{\mathrm{c}, \mathrm{d}}$ & 1 & 3 & 0.498 & 0.525 \\
\hline Tree age ${ }^{c, d}$ & 1 & 4 & 0.008 & 0.932 \\
\hline Last spray ratio $^{\mathrm{c}}$ & 1 & 6 & 8.187 & $0.031 *$ \\
\hline $\begin{array}{l}\text { Last spray ratio with monthly } \mathrm{IOBC} \\
\text { toxicity scores as covariate }{ }^{\mathrm{c}, \mathrm{d}}\end{array}$ & 1 & 4 & 1.145 & 0.350 \\
\hline Predictor & Wald & Chi-Square & $\mathrm{df}$ & $\mathrm{p}$ \\
\hline Total IOBC toxicity scores ${ }^{\mathrm{e}}$ & & 0.205 & 1 & 0.605 \\
\hline \multicolumn{5}{|c|}{$\begin{array}{l}{ }^{a} \text { Statistical model: repeated measures ANOVA with orchard, month, and orchard by month } \\
\text { interaction included as fixed effects. Abundance data were natural log transformed to obtain } \\
\text { more normally distributed residuals. }\end{array}$} \\
\hline \multicolumn{5}{|c|}{$\begin{array}{l}{ }^{\mathrm{b}} \text { Due to the significance of this interaction, we performed post-hoc tests to compare mean } \\
\text { abundance across orchards within each month. Results of paired comparison post-hoc tests are } \\
\text { summarized in Appendix Table A2. }\end{array}$} \\
\hline \multicolumn{5}{|c|}{$\begin{array}{l}{ }^{\mathrm{c}} \text { Statistical model: linear mixed model (LMM) with orchard included as random effect and } \\
\text { individual trees considered as subject effect. }\end{array}$} \\
\hline${ }^{\mathrm{d}}$ Monthly IOBC toxicity scores includ & as covariate. & & & \\
\hline
\end{tabular}




\section{FIGURES}

a) Monthly and total IOBC toxicity scores by orchard
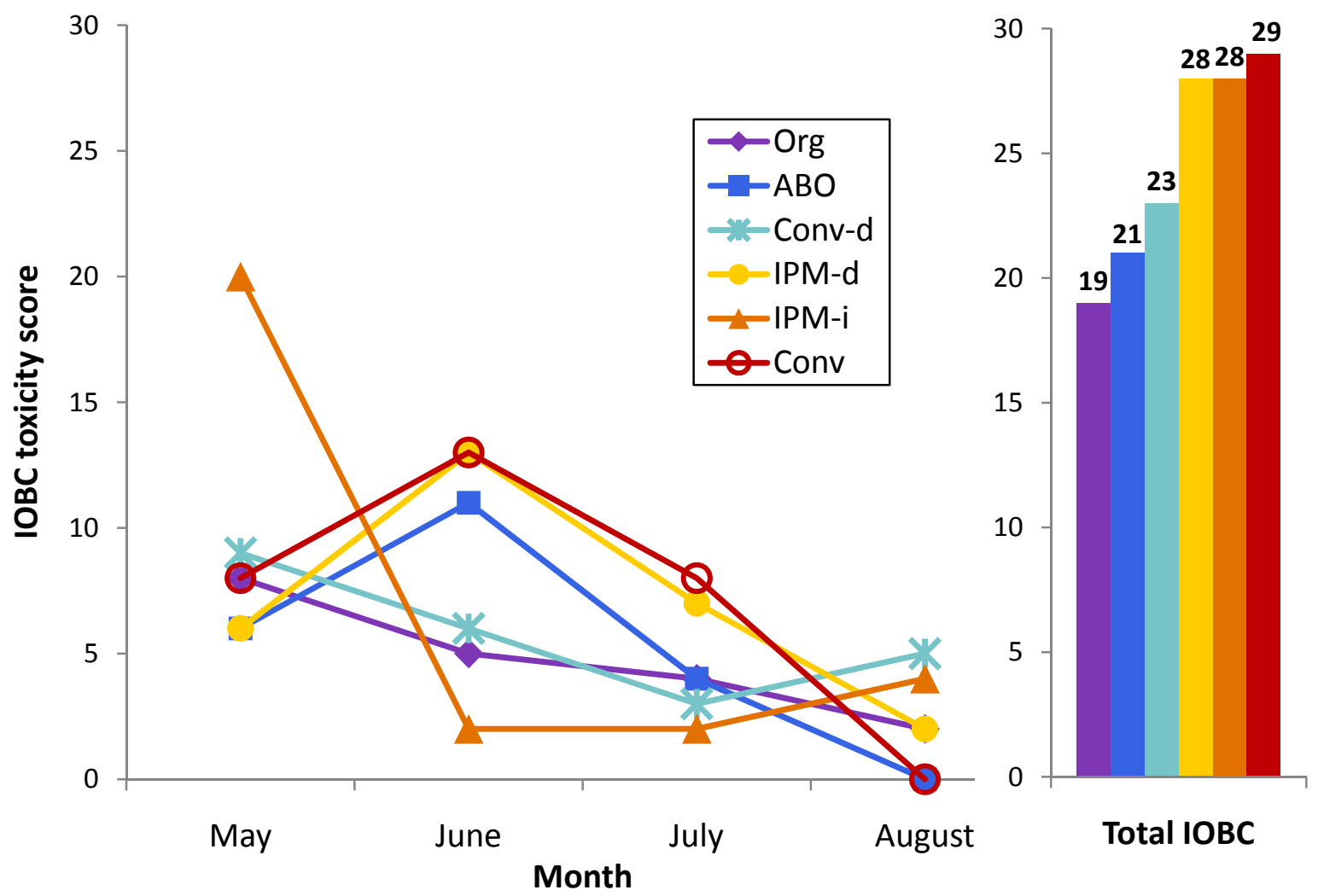

\section{b) Final IOBC toxicity gradient}

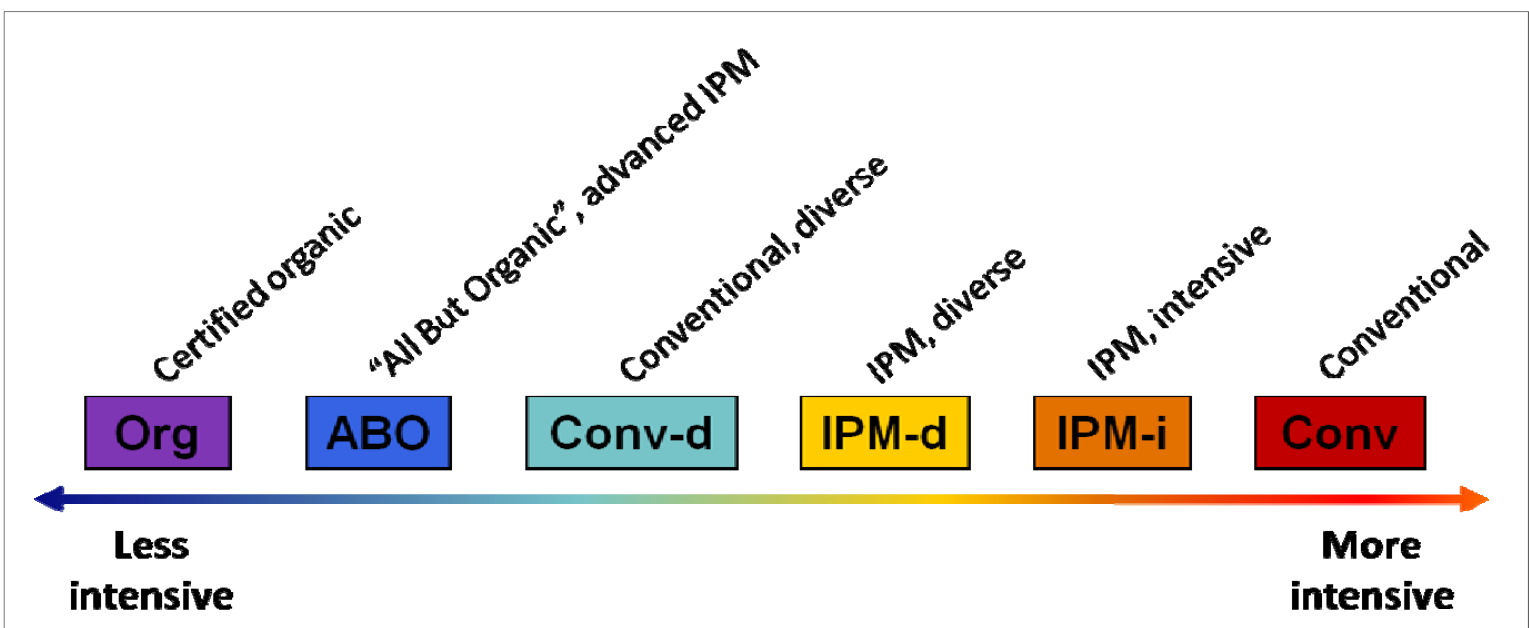

FIG. 1. a) IOBC wasp toxicity scores calculated for each orchard, by month and 2009 MayAugust season totals. IOBC toxicity scores were calculated by multiplying the IOBC toxicity class of each pesticide by the number of times applied, then summing up scores for different pesticides. Season total scores are indicated above each orchard bar.

b) Final toxicity gradient for the six orchards based on total IOBC toxicity scores. 


\section{a) Total species richness Jun-Aug 2009}

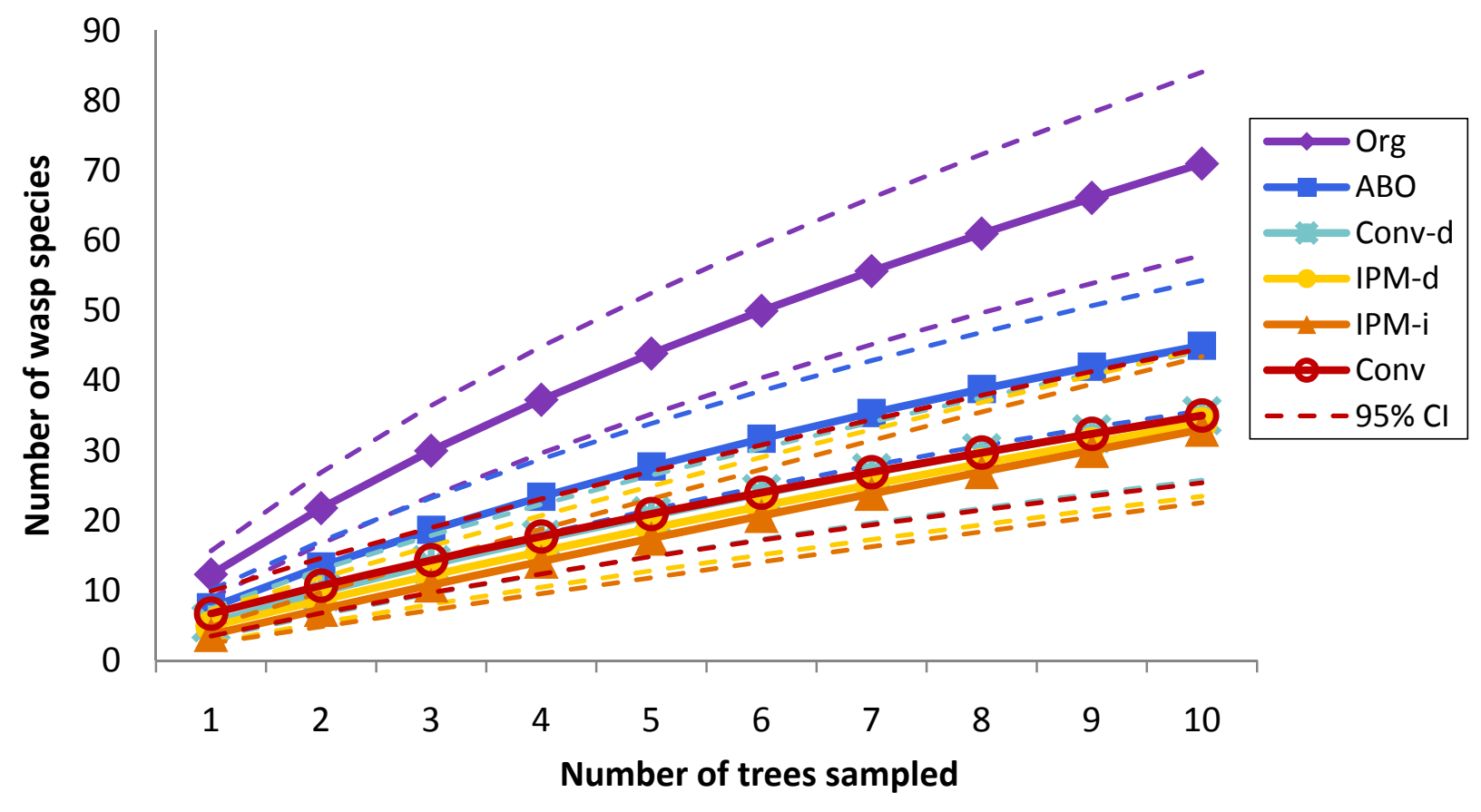

b) Variation in wasp species richness by month, 2009

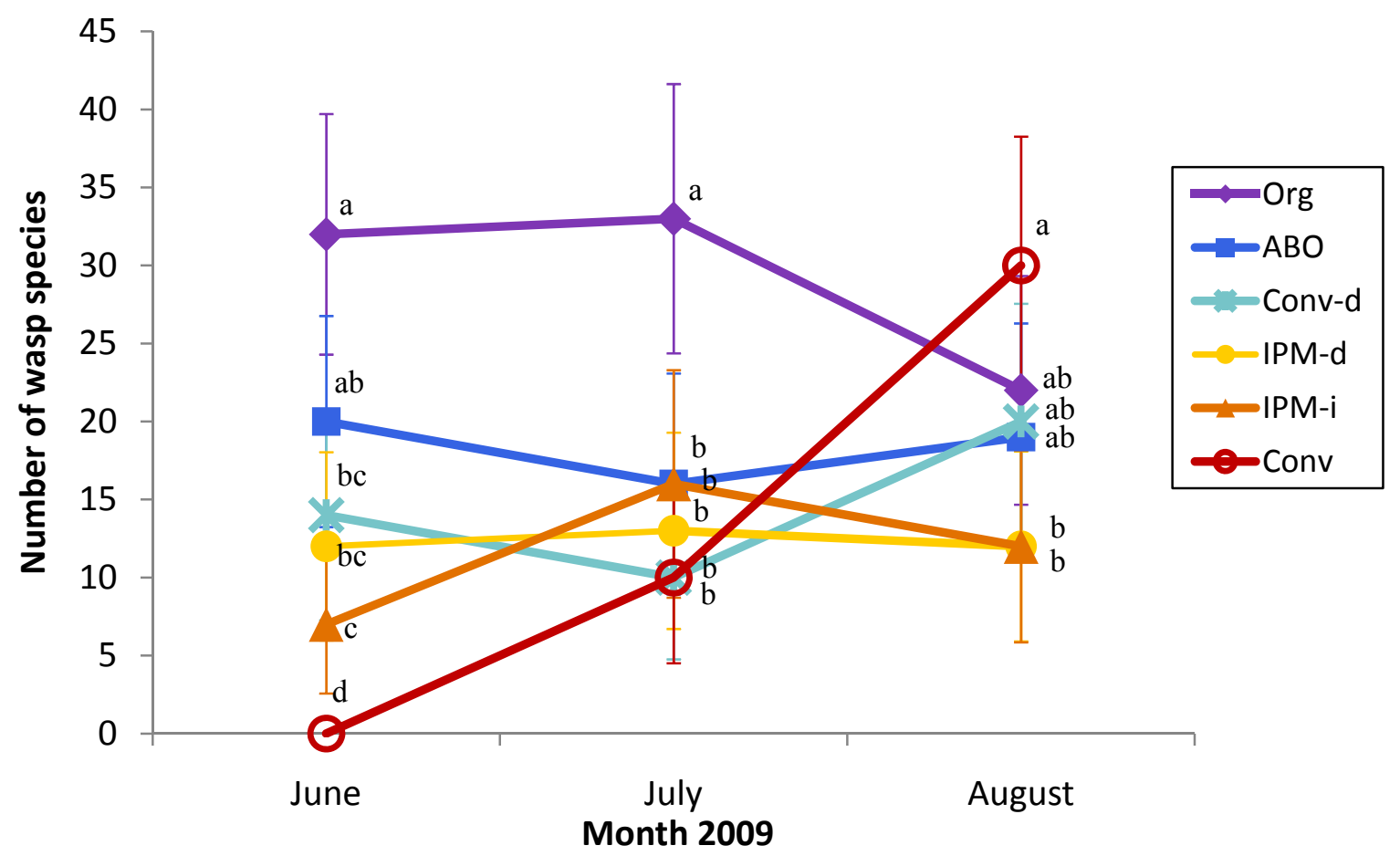

FIG. 2. a) Total parasitoid species richness from June through August 2009 at six apple orchards. Dotted lines represent $95 \%$ confidence intervals and indicate significantly higher species richness at Org than at the other five orchards.

b) Monthly variation in wasp species richness at the six orchards, using maximums from species accumulation curves for each month. Bars represent $95 \%$ confidence intervals. Orchards within the same month indicated by the same letter do not differ significantly from each other. 


\section{a) Mean wasp abundance per tree - 2009 totals}

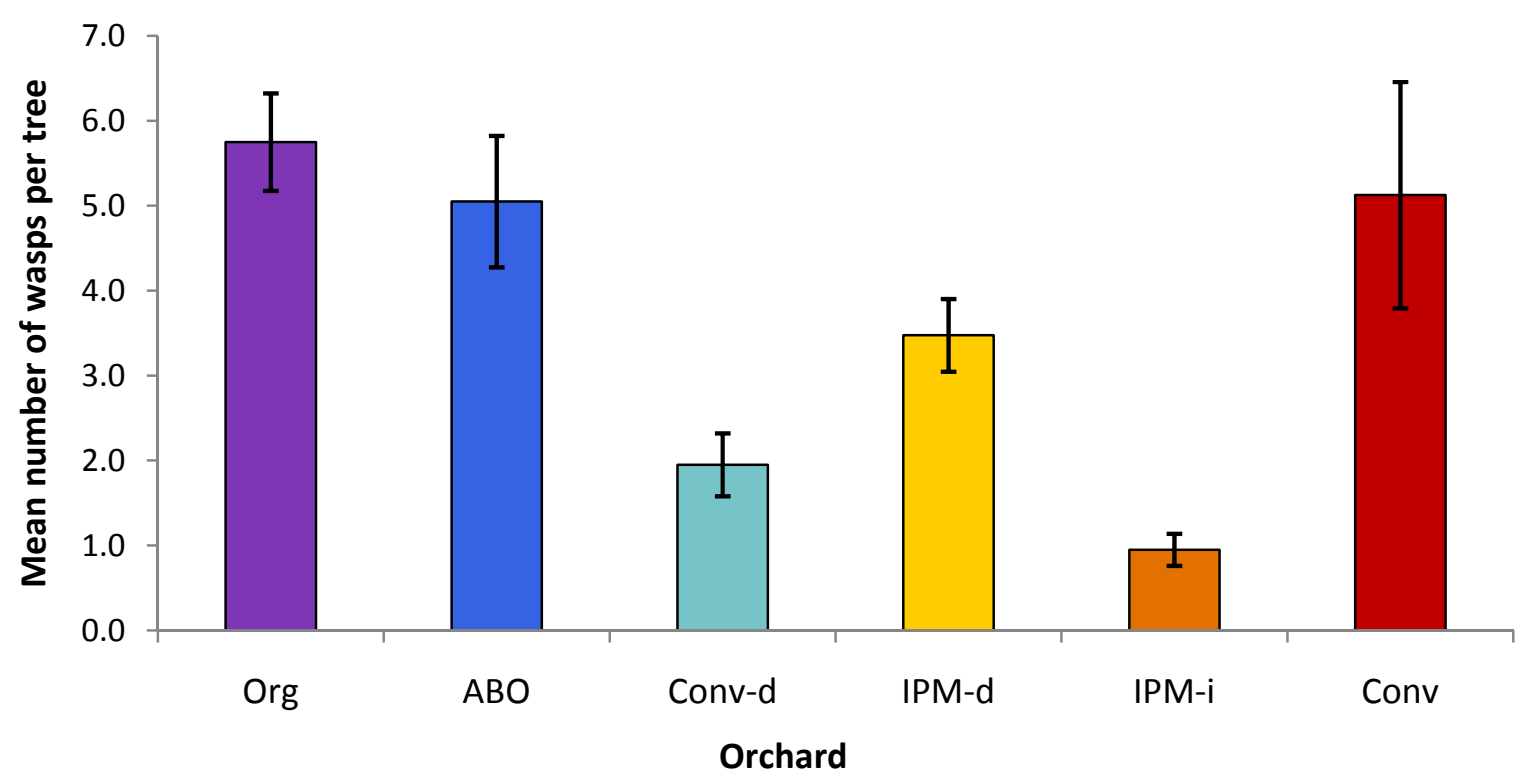

b) Monthly variation in mean wasp abundance per tree, 2009

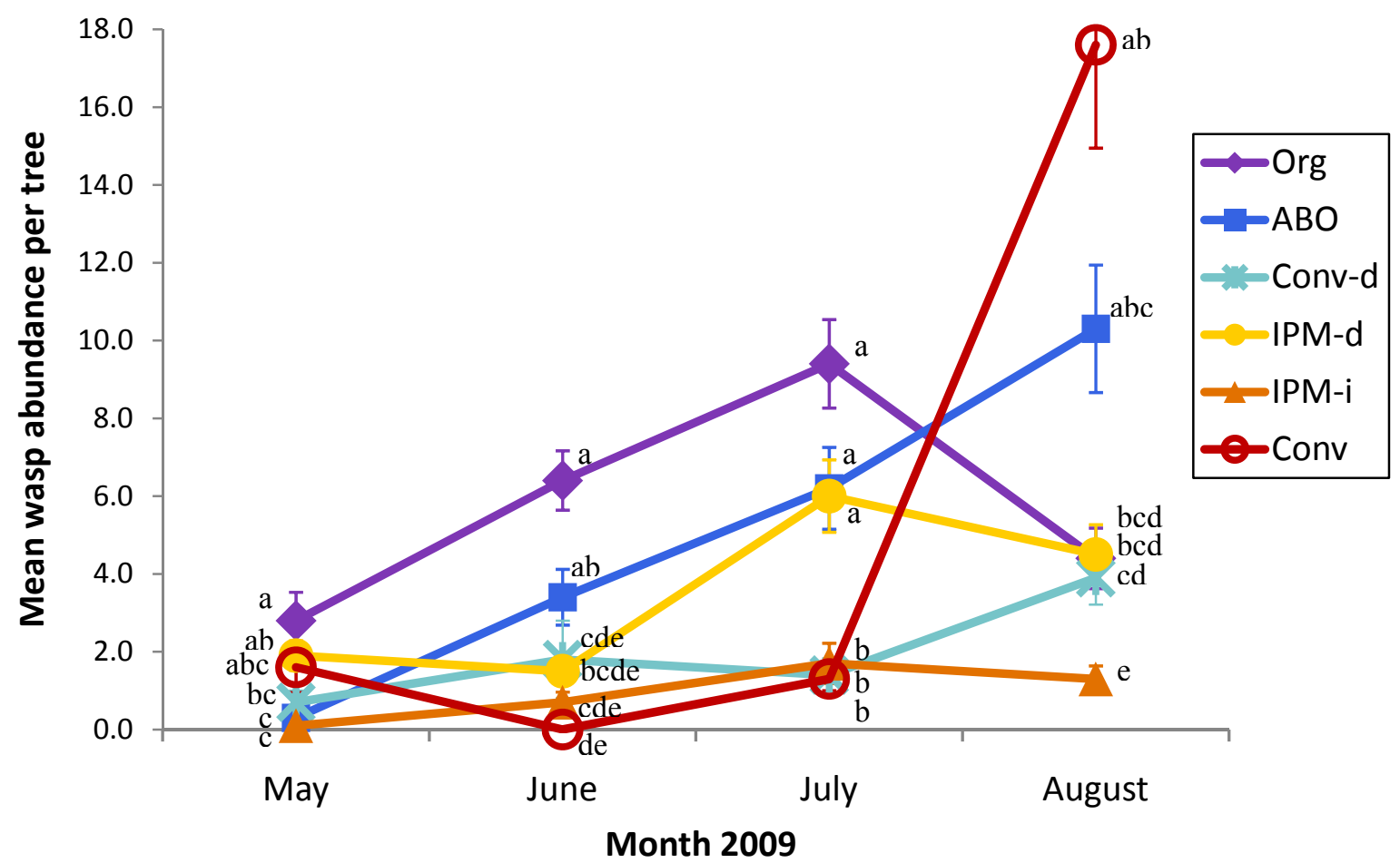

FIG. 3. a) Total mean wasp abundance per tree from May through August 2009 at six apple orchards. Bars represent standard errors.

b) Monthly variation in mean wasp abundance per tree at the six orchards. Bars represent standard errors. Orchards within the same month indicated by the same letter do not differ significantly from each other. Appendix Table A2 summarizes results from post-hoc pairwise comparisons of mean abundances across orchards within each month. 


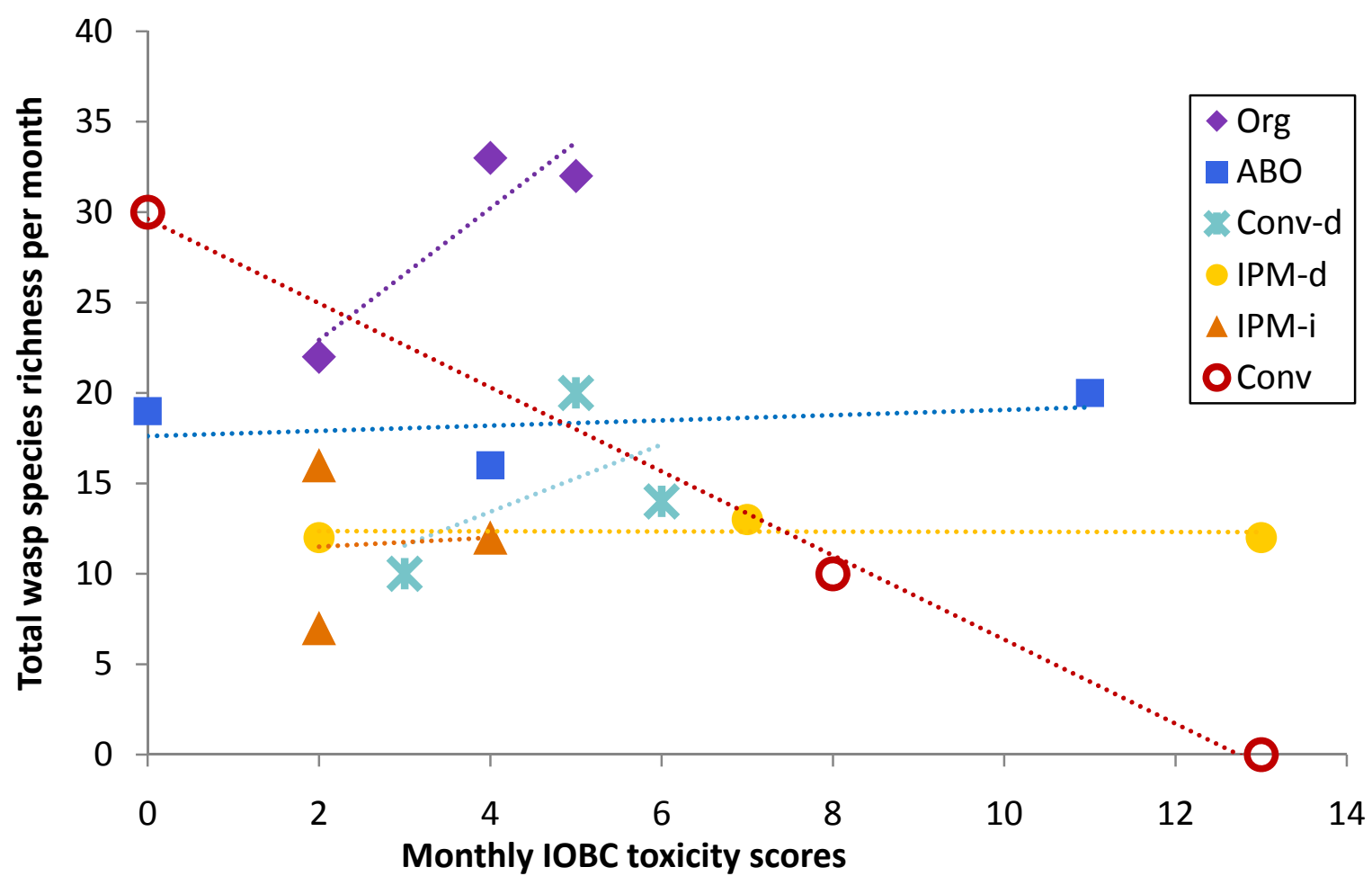

FIG. 4. Relationship between monthly IOBC toxicity scores and monthly counts of total parasitoid wasp species richness at six orchards from June through August 2009. A generalized linear mixed model did not find a significant relationship between monthly IOBC scores and species richness $(p=0.525$, Table 3$)$. Dotted lines indicate trendlines for individual orchards. 


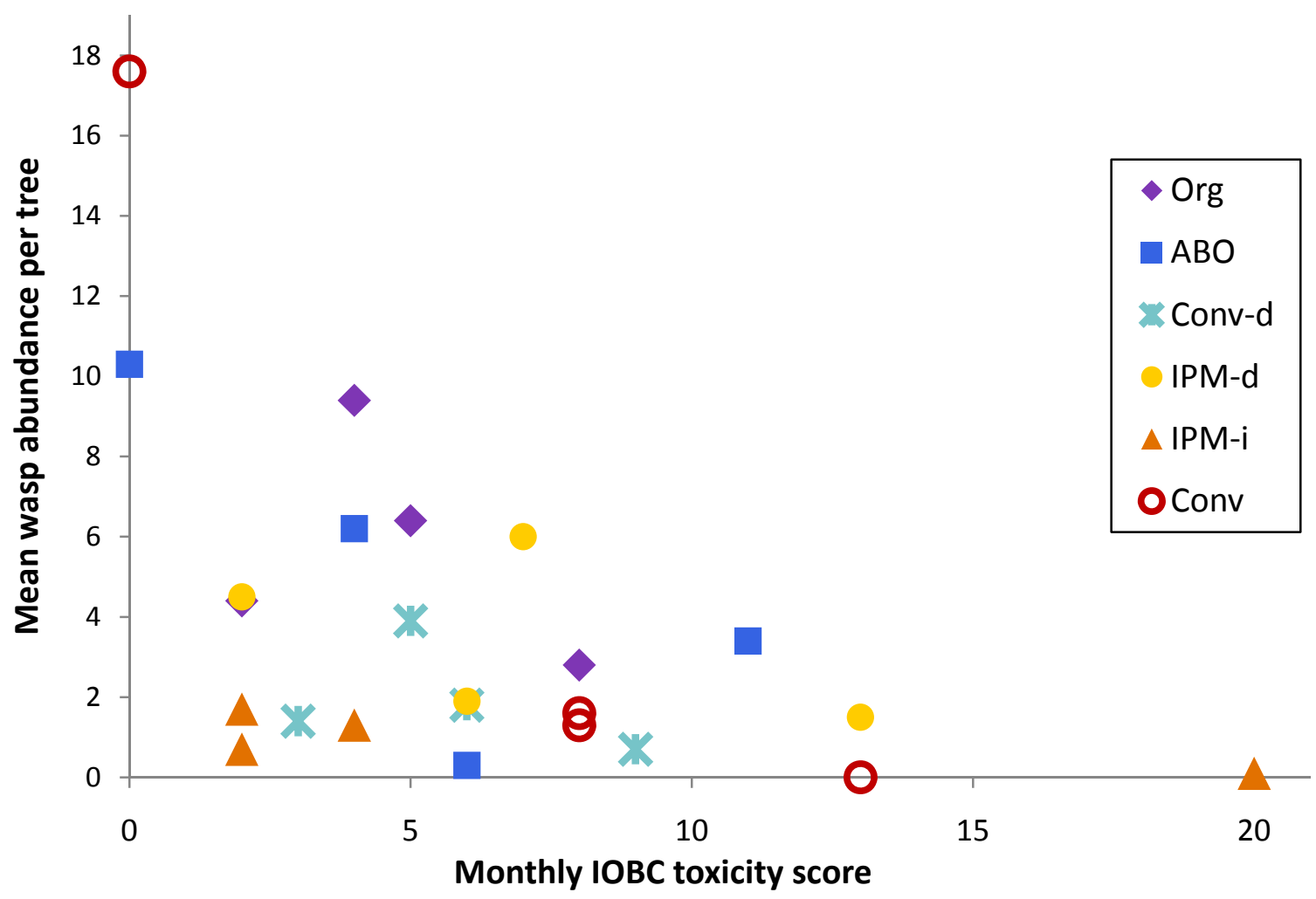

FIG. 5. Relationship between monthly IOBC pesticide toxicity scores and mean wasp abundance per tree at six orchards sampled from May through August 2009. A linear mixed model found a significant negative relationship between monthly IOBC toxicity scores and natural $\log$ transformed abundance $(\mathrm{p}=0.014$, Table 4$)$. Mean abundance per tree is presented in this figure for clarity. 


\section{Org: 202 individuals}

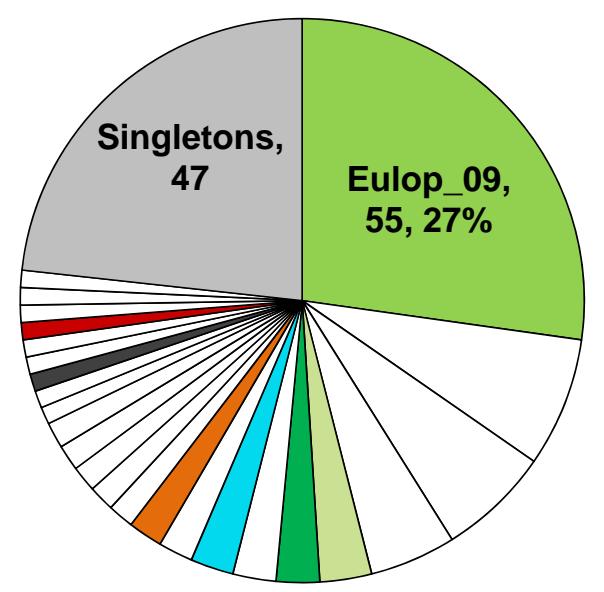

IPM-d: 118 individuals

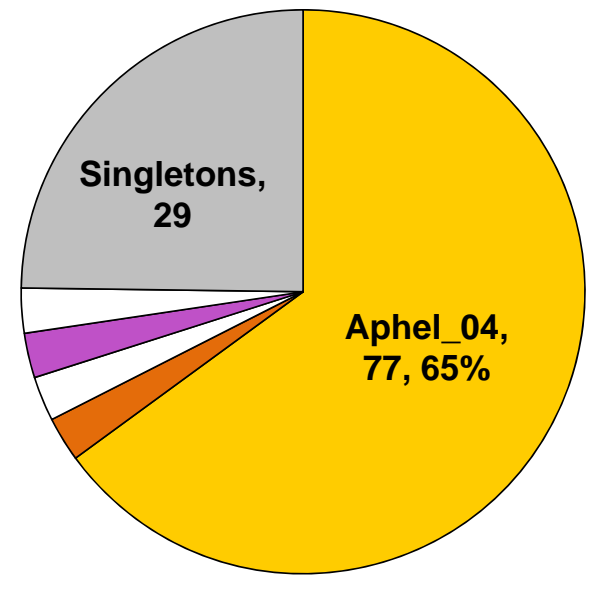

ABO: 198 individuals

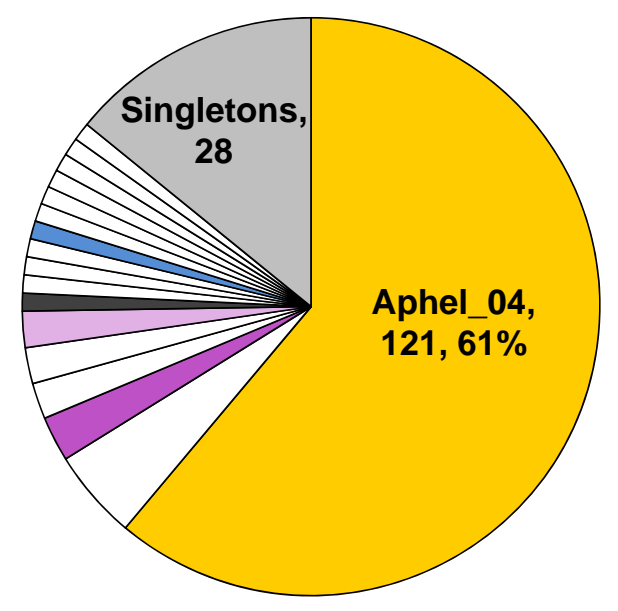

IPM-i: $\mathbf{3 7}$ individuals

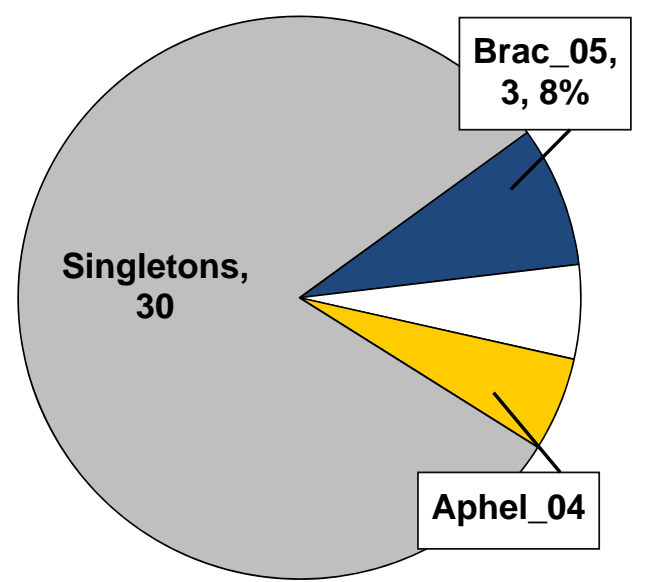

Conv-d: 69 individuals

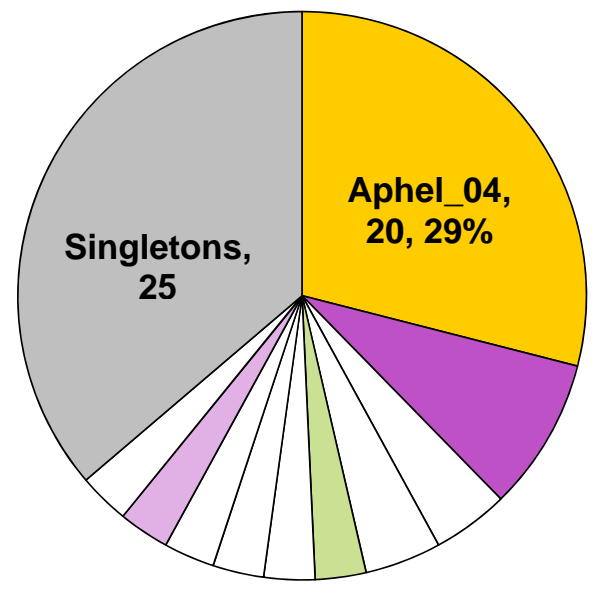

Conv: 187 individuals

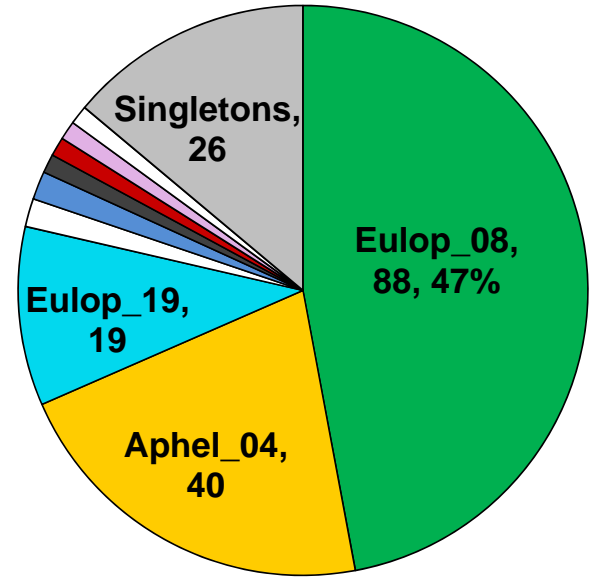

FIG. 6. Wasp morphospecies composition in six orchards. Total number of wasp individuals per orchard is indicated above each pie chart. The dominant species per orchard is marked with number of wasps and percentage of total wasps in that orchard; other species that represent $10 \%$ or more of total individuals are indicated by name and number of wasps. Singletons are grouped as one category per orchard. Unlabeled colored segments indicate shared species with $>1$ individuals per orchard; white segments indicate species that either occurred in only one orchard or only occurred as singletons in other orchards. Aphel_04 was collected from all orchards except Org. 


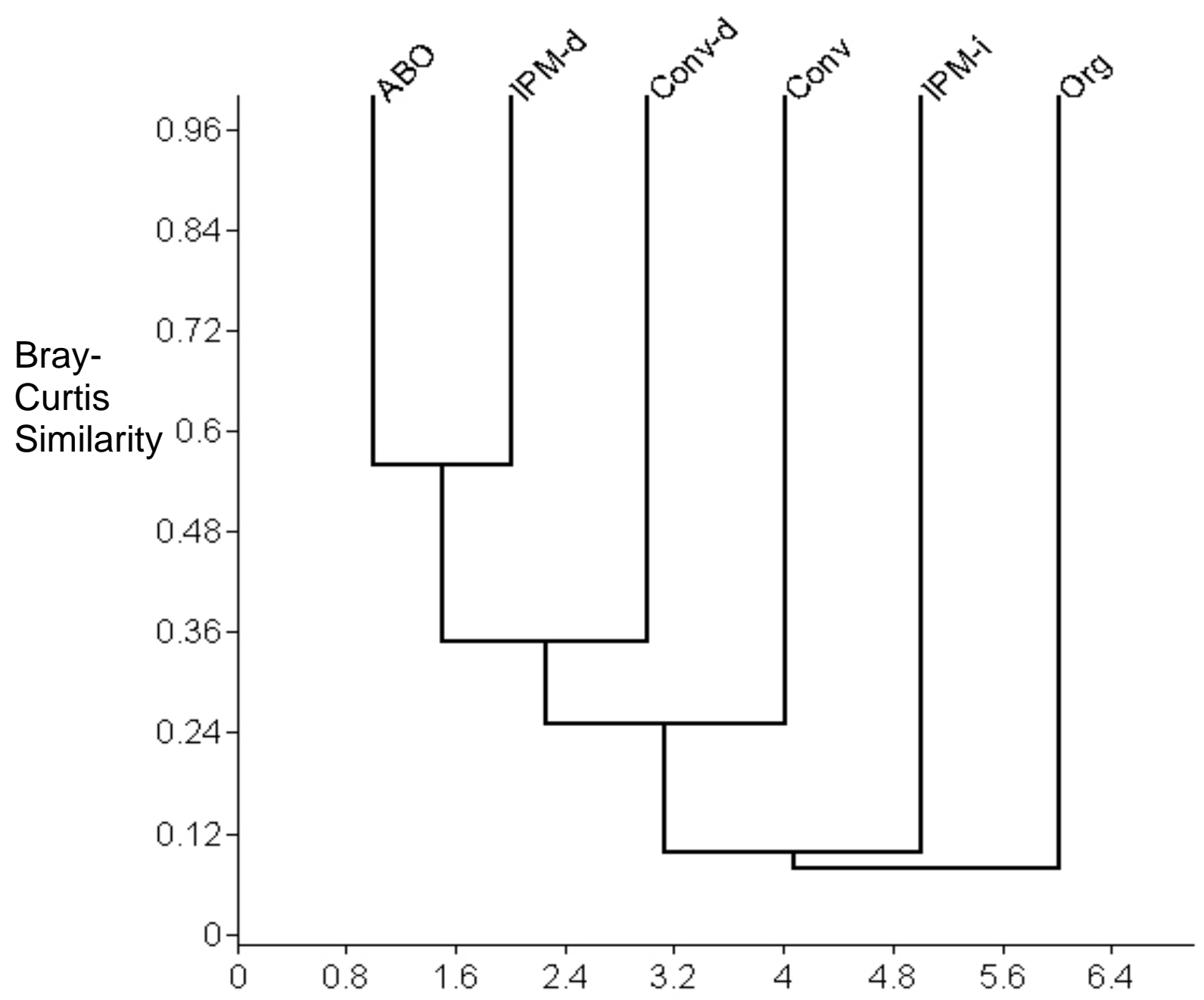

FIG. 7. Paired group cluster analysis for the six orchards based on Bray-Curtis species dissimilarity indices for seasonal total wasp species composition June-August 2009. Higher Bray-Curtis values indicate more similar wasp species composition between orchards. 


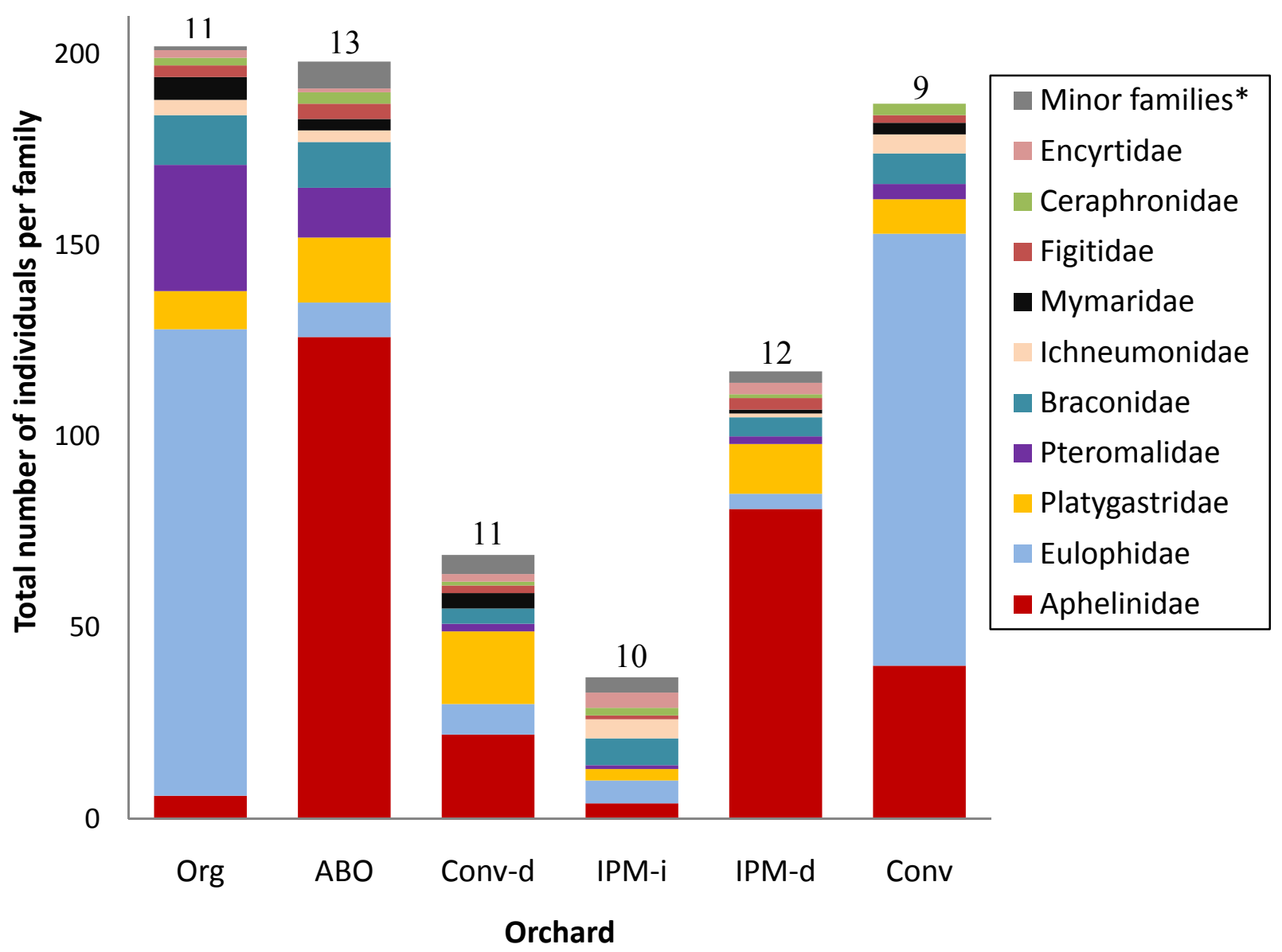

FIG. 8. Wasp family composition in the six orchards. Total number of families per orchard is indicated above each bar. *Minor families (Diapriidae, Eurytomidae, Megaspilidae, Eucharitidae, Sierolomorphidae and Torymidae) are represented by $\leq 3$ individuals per orchard. 


\section{LiTERATURE Cited}

Agnello, A. M., W. H. Reissig, J. Kovach, and J. P. Nyrop. 2003. Integrated apple pest management in New York State using predatory mites and selective pesticides. Agriculture, Ecosystems and Environment 94:183-195.

Altieri, M. A., and L. L. Schmidt. 1986. The dynamics of colonizing arthropod communities at the interface of abandoned, organic and commercial apple orchards and adjacent woodland habitats. Agriculture, Ecosystems and Environment 16:29-43.

Atanassov, A., P. W. Shearer, and G. C. Hamilton. 2003. Peach pest management programs impact beneficial fauna abundance and Grapholita molesta (Lepidoptera: Tortricidae) egg parasitism and predation. Environmental Entomology 32:780-788.

Bastos, C. S., R. P. de Almeida, and F. Suinaga. 2006. Selectivity of pesticides used on cotton (Gossypium hirsutum) to Trichogramma pretiosum reared on two laboratory-reared hosts. Pest Management Science 62:91-98.

Bengtsson, J., J. Ahnström, and A. Weibull. 2005. The effects of organic agriculture on biodiversity and abundance: a meta-analysis. Journal of Applied Ecology 42:261-269.

Bianchi, F. J. J. A., C. J. H. Booij, and T. Tscharntke. 2006. Sustainable pest regulation in agricultural landscapes: a review on landscape composition, biodiversity and natural pest control. Proceedings of the Royal Society of Biological Sciences 273:1715-1727.

Biddinger, D. J., C. M. Felland, and L. A. Hull. 1994. Parasitism of tufted apple bud moth (Lepidoptera: Tortricidae) in conventional insecticide and pheromone-treated Pennsylvania apple orchards. Environmental Entomology 23:1568-1579.

Borror, D. J., C. A. Triplehorn, and N. F. Johnson. 1989. An introduction to the study of insects. Sixth edition. Thomson Learning, USA.

Borror, D. J., and R. E. White. 1970. A field guide to the insects America north of Mexico. Houghton Mifflin, New York, Ney York, USA.

Bray, J. R., and J. T. Curtis. 1957. An ordination of the upland forest communities of southern Wisconsin. Ecological Monographs 4:326-349.

Brown, M. W. 1993. Resilience of the natural arthropod community on apple to external disturbance. Ecological Entomology 18:169-183.

Brown, M. W., and C. R. Matthews. 2007. Conservation biological control of rosy apple aphid, Dysaphis plantaginea (Passerini) in eastern North America. Environmental Entomology 
36:1131-1139.

Brown, M. W., and J. J. Schmitt. 2001. Seasonal and diurnal dynamics of beneficial insect populations in apple orchards under different management intensity. Environmental Entomology 30:415-424.

Carmo, E. L., A. F. Bueno, and R. C. O. F. Bueno. 2010. Pesticide selectivity for the insect egg parasitoid Telenomus remus. BioControl 55:455-464.

Colwell, R. K. 2006. EstimateS: Statistical estimation of species richness and shared species from samples. Version 8. Persistent URL < purl.oclc.org/estimates>.

Cook, S. M., Z. R. Khan, and J. A. Pickett. 2007. The use of push-pull strategies in integrated pest management. Annual Review of Entomology 52:375-400.

Cross, J. V., M. G. Solomon, D. Babandreier, L. Blommers, M. A. Easterbrook, C. N. Jay, G. Jenser, R. L. Jolly, U. Kuhlmann, R. Lilley, E. Olivella, S. Toepfer, and S. Vidal. 1999. Biocontrol of pests of apples and pears in northern and central Europe: 2. Parasitoids. Biocontrol Science and Technology 9:277-314.

Crowder, D. W., T. D. Northfield, M. R. Strand, and W. E. Snyder. 2010. Organic agriculture promotes evenness and natural pest control. Nature 466:109-113.

Estay, P., J. E. Araya, and M. H. Araya. 2005. Toxicidad en laboratorio de imidacloprid, acetamiprid y abamectina sobre adultos de Encarsia formosa (Gahan) (Hymenoptera, Aphelinidae). Boletín Sociedad Entomológica Aragonesa 37:369-371.

Franz, J. M., H. Bogenschütz, S. A. Hassan, P. Huang, E. Naton, H. Suter, and G. Viggiani. 1980. Results of a joint pesticide test programme by the Working Group: Pesticides and Beneficial Arthropods. Entomophaga 25:231-236.

Grissell, E. E., and M. E. Schauff. 1990. A handbook of the families of Nearctic Chalcidoidea (Hymenoptera). The Entomological Society of Washington, Washington, D. C., USA.

Gut, L. J., and J. F. Brunner. 1998. Pheromone-based management of codling moth (Lepidoptera: Tortricidae) in Washington apple orchards. Journal of Agricultural Entomology 15:387-405.

Hammer, O., D. A. T. Harper, and P. D. Ryan. 2001. PAST: paleontological statistics software package for education and data analysis. Palaeontologia Electronica 4:9pp.

Harper, C. A., and D. C. Guynn, Jr. 1998. A terrestrial vacuum sampler for macroinvertebrates. Wildlife Society Bulletin 26:302-306. 
Hassan, S. A., F. Bigler, H. Bogenschütz, J. U. Brown, S. I. Firth, P. Huang, M. S. Ledieu, E. Naton, P. A. Oomen, W. P. J. Overmeer, W. Rieckmann, L. Samsøe-Petersen, G. Viggiani, and A. Q. van Zon. 1983. Results of the second joint pesticide testing programme by the IOBC/WPRS-Working Group "Pesticides and Beneficial Arthropods." Zeitschrift fur Angewandte Entomologie 95:151-158.

Hassan, S. A., R. Albert, F. Bigler, P. Blaisinger, H. Bogenschütz, E. Boller, J. Brun, P. Chiverton, P. Edwards, W. D. Englert, P. Huang, C. Inglesfield, E. Naton, P. A. Oomen, W. P. J. Overmeer, W. Rieckmann, L. Samsøe-Petersen, J. J. Tuset, G. Viggiani, and G. Vanwetswinkel. 1987. Results of the third joint pesticide testing programme by the IOBC/WPRS-Working Group "Pesticides and Beneficial Arthropods.” Journal of Applied Entomology 103:92-107.

Hassan, S. A., F. Bigler, H. Bogenschütz, E. Boller, J. Brun, P. Chiverton, P. Edwards, F. Mansour, E. Naton, P. A. Oomen, W. P. J. Overmeer, L. Polgar, W. Rieckmann, L. Samsøe-Petersen, A. Stäubli, G. Sterk, K. Tavares, J. J. Tuset, G. Viggiani, and A. G. Vivas. 1988. Results of the 4th joint pesticide testing programme carried out by the IOBC/WPRS-Working Group "Pesticides and Beneficial Organisms.” Journal of Applied Entomology 105:321-329.

Hassan, S. A., F. Bigler, H. Bogenschütz, E. Boller, J. Brun, J. N. M. Calis, J. CoremansPelseneer, C. Duso, A. Grove, U. Heimbachi, N Helver, H. Hokkanen, G. B. Lewis, F. Mansour, L. Moreth, L. Polgar, L. Samsøe-Petersen, B. Sauphanor, A. Stäubli, G. Sterk, A. Vainio, M. van de Veire, G. Viggiani, and H. Vogt. 1994. Results of the sixth joint pesticide testing programme of the IOBC/WPRS-Working Group "Pesticides and Beneficial Organisms.” Entomophaga 39:107-119.

Hole, D. G., A. J. Perkins, J. D. Wilson, I. H. Alexander, P. V. Grice, and A. D. Evans. 2005. Does organic farming benefit biodiversity? Biological Conservation 122:113-130.

Holzschuh, A., I. Steffan-Dwenter, and T. Tscharntke. 2010. How do landscape composition and configuration, organic farming and fallow strips affect the diversity of bees, wasps and their parasitoids? Journal of Animal Ecology 79:491-500.

Hooper, D. U., F. S. Chapin, III, J. J. Ewel, A. Hector, P. Inchausti, S. Lavorel, J. H. Lawton, D. M. Lodge, M. Loreau, S. Naeem, B. Schmid, H. Setälä, A. J. Symstad, J. Vandermeer, and D. A. Wardle. 2005. Effects of biodiversity on ecosystem functioning: a consensus of 
current knowledge. Ecological Monographs 75:3-35.

Hull, L. A., B. A. McPheron, and A. M. Lake. 1997. Insecticide resistance management and integrated mite management in orchards: can they coexist? Pesticide Science 51:359-366.

Jones, V. P., T. R. Unruh, D. R. Horton, N. J. Mills, J. F. Brunner, E. H. Beers, and P. W. Shearer. 2009. Tree fruit IPM programs in the western United States: the challenges of enhancing biological control through intensive management. Pest Management Science 65:1263-1377.

Koss, A. M., A. S. Jensen, A. Schreiber, K. S. Pike, and W. E. Snyder. 2005. Comparison of predator and pest communities in Washington potato fields treated with broad-spectrum, selective, or organic insecticides. Environmental Entomology 34:87-95.

Lacey, L. A., and T. R. Unruh. 2005. Biological control of codling moth (Cydia pomonella, Lepidoptera: Tortricidae) and its role in integrated pest management, with emphasis on entomopathogens. Vedalia 12:33-60.

Landis, D. A., S. D. Wratten, and G. M. Gurr. 2000. Habitat management to conserve natural enemies of arthropod pests in agriculture. Annual Review of Entomology 45:175-201.

LaSalle, J. 1993. Parasitic Hymenoptera, biological control and biodiversity. In LaSalle, J., and I. D. Gauld. 1993. Hymenoptera and biodiversity. CAB International, Wallingford, England.

Letourneau, D. K., and S. G. Bothwell. 2008. Comparison of organic and conventional farms: challenging ecologists to make biodiversity functional. Frontiers in Ecology and the Environment 6:430-438.

Longley, M. 1999. A review of pesticide effects upon immature aphid parasitoids within mummified hosts. International Journal of Pest Management 45:139-145.

Macfadyen, S., R. Gibson, A. Polaszek, R. J. Morris, P. G. Craze, R. Planqué, W. O. C. Symondson, and J. Memmott. 2009. Do differences in food web structure between organic and conventional farms affect the ecosystem service of pest control? Ecology Letters 12:229-238.

MacPhee, A. W., and K. H. Sanford. 1954. The influence of spray programs on the fauna of apple orchards in Nova Scotia. VII. Effects on some beneficial arthropods. The Canadian Entomologist 86:128-135.

Mani, M., and A. Krishnamoorthy. 1997. Effects of different pesticides upon the wax scale 
parasitoid, Anicetus ceylonensis How. (Hym.: Encyrtidae). International Journal of Pest Management 43:123-126.

Manzoni, C. G., A. D. Grützmacher, F. P. Giolo, W. da Roza Härter, and C. Müller. 2006. Selectividade de agrotóxicos usados na produção integrada de maçã para adultos de Trichogramma pretiosum. Pesquisa Agropecuária Brasileira 41:1461-1467.

Markó, V., B. Keresztes, M. T. Fountain, and J. V. Cross. 2009. Prey availability, pesticides and the abundance of orchard spider communities. Biological Control 48:115-124.

Miliczky, E. R., and D. R. Horton. 2005. Densities of beneficial arthropods within pear and apple orchards affected by distance from adjacent native habitat and association of natural enemies with extra-orchard host plants. Biological Control 33:249-259.

Molenberghs, G., and G. Verbeke. 2000. Linear mixed models for longitudinal data. Springer, New York, NY, USA.

Molenberghs, G., and G. Verbeke. 2005. Models for discrete longitudinal data. Springer, New York, NY, USA.

Perry, R., J. Flore, M. Whalon, J. Johnson, A. Jones, G. Van Ee, and C. Edson. 1996. The development of integrated fruit management programs in Michigan, USA. Acta Horticulturae 422:85-89.

Preetha, G., J. Stanley, S. Suresh, S. Kuttalam, and R. Samiyappan. 2009. Toxicity of selected insecticides to Trichogramma chilonis: assessing their safety in the rice ecosystem. Phytoparasitica 37:209-215.

Prokopy, R. J. 1994. Integration in orchard pest and habitat management: a review. Agriculture, Ecosystems and Environment 50:1-10.

Prokopy, R. J., J. L. Mason, M. Christie, and S. E. Wright. 1996. Arthropod pest and natural enemy abundance under second-level versus first-level integrated pest management practices in apple orchards: a 4-year study. Agriculture, Ecosystems and Environment $57: 35-47$.

Sarvary, M. A., J. Nyrop, H. Reissig, and K. M. Gifford. 2007. Potential for conservation biological control of the obliquebanded leafroller (OBLR) Choristoneura rosaceana (Harris) in orchard systems managed with reduced-risk insecticides. Biological Control 40:37-47.

Simon, S., H. Defrance, and B. Sauphanor. 2007. Effect of codling moth management on orchard 
arthropods. Agriculture, Ecosystems and Environment 122:340-348.

Sterk, G., S. A. Hassan, M. Baillod, F. Bakker, F. Bigler, S. Blümel, H. Bogenschütz, E. Boller, B. Bromand, J. Brun, J. N. M. Calis, J. Coremans-Pelseneer, C. Duso, A. Garrido, A. Grove, U. Heimbach, H. Hokkanen, J. Jacas, G. Lewis, L. Moreth, L. Polgar, L. Roversti, L. Samsoe-Petersen, B. Sauphanor, L. Schaub, A. Stäubli, J. J. Tuset, A. Vainio, M. Van de Veire, G. Viggiani, E. Viñuela, and H. Vogt. 1999. Results of the seventh joint pesticide testing programme carried out by the IOBC/WPRS-Working Group 'Pesticides and Beneficial Organisms.’ BioControl 44:99-117.

Suckling, D. M., J. T. S. Walker, and C. H. Wearing. 1999. Ecological impact of three pest management systems in New Zealand apple orchards. Agriculture, Ecosystems and Environment 73:129-140.

Suma, P., L. Zappalà, G. Mazzeo, and G. Siscaro. 2009. Lethal and sub-lethal effects of insecticides on natural enemies of citrus scale pests. BioControl 54:651-661.

Thomson, L. J., and A. A. Hoffman. 2006. Field validation of laboratory-derived IOBC toxicity ratings for natural enemies in commercial vineyards. Biological Control 39:507-515.

Thomson, L. J., and A. A. Hoffman. 2007. Ecologically sustainable chemical recommendations for agricultural pest control? Journal of Economic Entomology 100:1741-1750.

Tscharntke, T., R. Bommarco, Y. Clough, T. O. Crist, D. Kleijn, T. A. Rand, J. M. Tylianakis, S. van Nouhuys, and S. Vidal. 2008. Reprint of "Conservation biological control and enemy diversity on a landscape scale" [Biol. Control 43 (2007) 294-309]. Biological Control 45:238-253.

VanDriesche, R. G., and G. Taub. 1983. Impact of parasitoids on Phyllonorycter leafminers infesting apple in Massachusettes, U.S.A. Protection Ecology 5:303-317.

Wilkinson, T. K., D. A. Landis, and L. J. Gut. 2004. Parasitism of obliquebanded leafroller (Lepidoptera: Tortricidae) in commercially managed Michigan apple orchards. Journal of Economic Entomology 97:1524-1530.

Williams III, L., L. D. Price, and V. Manrique. 2003. Toxicity of field-weathered insecticide residues to Anaphes iole (Hymenoptera: Mymaridae), and egg parasitoid of Lygus lineolaris (Heteroptera: Miridae), and implications for inundative biological control in cotton. Biological Control 26:217-223 
TABLE A1. Parasitic Hymenoptera morphospecies and families identified from vacuum-sampling of apple tree canopies at six orchards in southeastern Michigan, USA, May-August 2009.

\begin{tabular}{|c|c|c|c|c|c|c|c|}
\hline \multirow[b]{2}{*}{ Family, morphospecies } & \multicolumn{7}{|c|}{ Number of wasps per orchard } \\
\hline & Org & $\mathrm{ABO}$ & Conv-d & IPM-d & IPM-i & Conv & Total \\
\hline \multicolumn{8}{|l|}{ Aphelinidae } \\
\hline Aphel_01 & 1 & 0 & 0 & 1 & 0 & 0 & 2 \\
\hline Aphel_02 & 0 & 0 & 0 & 0 & 1 & 0 & 1 \\
\hline Aphel_04 & 0 & 121 & 20 & 77 & 2 & 40 & 260 \\
\hline Aphel_05 & 4 & 1 & 1 & 3 & 0 & 0 & 9 \\
\hline Aphel_06 & 1 & 4 & 1 & 1 & 0 & 0 & 7 \\
\hline Aphel_07 & 0 & 0 & 0 & 0 & 1 & 0 & 1 \\
\hline \multicolumn{8}{|l|}{ Braconidae } \\
\hline Brac_01 & 1 & 0 & 0 & 0 & 0 & 1 & 2 \\
\hline Brac_02 & 0 & 0 & 1 & 0 & 0 & 0 & 1 \\
\hline Brac_03 & 0 & 0 & 0 & 3 & 0 & 0 & 3 \\
\hline Brac_04 & 1 & 0 & 0 & 0 & 0 & 0 & 1 \\
\hline Brac_05 & 0 & 0 & 0 & 0 & 3 & 0 & 3 \\
\hline Brac_06 & 0 & 0 & 0 & 0 & 1 & 0 & 1 \\
\hline Brac_07 & 0 & 2 & 0 & 0 & 0 & 0 & 2 \\
\hline Brac_08 & 0 & 2 & 0 & 0 & 0 & 0 & 2 \\
\hline Brac_09 & 0 & 1 & 0 & 0 & 0 & 0 & 1 \\
\hline Brac_10 & 0 & 1 & 0 & 0 & 0 & 0 & 1 \\
\hline Brac_11 & 0 & 1 & 0 & 0 & 0 & 1 & 2 \\
\hline Brac_12 & 0 & 1 & 0 & 0 & 0 & 0 & 1 \\
\hline Brac_13 & 0 & 1 & 0 & 0 & 0 & 0 & 1 \\
\hline Brac_14 & 0 & 2 & 0 & 0 & 0 & 3 & 5 \\
\hline Brac_15 & 0 & 0 & 0 & 1 & 0 & 0 & 1 \\
\hline Brac_16 & 0 & 1 & 0 & 0 & 0 & 0 & 1 \\
\hline Brac_17 & 0 & 0 & 0 & 0 & 1 & 0 & 1 \\
\hline Brac_18 & 3 & 0 & 0 & 0 & 0 & 0 & 3 \\
\hline Brac_19 & 1 & 0 & 0 & 0 & 0 & 0 & 1 \\
\hline Brac_20 & 1 & 0 & 0 & 0 & 0 & 0 & 1 \\
\hline Brac_21 & 0 & 0 & 0 & 0 & 1 & 0 & 1 \\
\hline Brac_22 & 0 & 0 & 0 & 1 & 0 & 0 & 1 \\
\hline Brac_23 & 0 & 0 & 0 & 0 & 1 & 0 & 1 \\
\hline Brac_24 & 0 & 0 & 1 & 0 & 0 & 0 & 1 \\
\hline Brac_25 & 0 & 0 & 1 & 0 & 0 & 0 & 1 \\
\hline Brac_26 & 0 & 0 & 0 & 0 & 0 & 1 & 1 \\
\hline Brac_27 & 0 & 0 & 0 & 0 & 0 & 1 & 1 \\
\hline Brac_28 & 0 & 0 & 0 & 0 & 0 & 1 & 1 \\
\hline Brac_29 & 0 & 0 & 1 & 0 & 0 & 0 & 1 \\
\hline
\end{tabular}


Appendix - Table A1

\begin{tabular}{lrrrrrrr}
\hline Family, morphospecies & Org & ABO & Conv-d & IPM-d & IPM-i & Conv & Total \\
\hline Brac_30 & 5 & 0 & 0 & 0 & 0 & 0 & 5 \\
Brac_31 & 1 & 0 & 0 & 0 & 0 & 0 & 1 \\
Ceraphronidae & & & & & & & \\
Cera_01 & 0 & 1 & 0 & 0 & 1 & 0 & 2 \\
Cera_02 & 0 & 0 & 0 & 0 & 1 & 1 & 2 \\
Cera_03 & 1 & 0 & 0 & 0 & 0 & 0 & 1 \\
Cera_04 & 1 & 2 & 1 & 1 & 0 & 1 & 6 \\
Cera_05 & 0 & 0 & 0 & 0 & 0 & 1 & 1
\end{tabular}

Chalcidoidea, unknown family

ChalX_07
ChalX_08

Diapriidae

Dia_01

Dia_02

Dia_03

Dia_04
0

0
0

2

2
1

1
0

0

0

0

0

Encyrtidae

Encyr_01

Encyr_02

Encyr_03

Encyr_04

Encyr_05

Encyr_06

Encyr_07

Encyr_08

Eucharitidae

Euch_01

Eulophidae

Eulop_01

Eulop_02

Eulop_04

Eulop_05

Eulop_06

Eulop_07

Eulop_08

Eulop_09

Eulop_10

Eulop_11

Eulop_12

Eulop_13

0
0
0
1
0
0

0

0

1

0

0

$0 \quad 0$

10

0

0

0

1

0

0

1

$\begin{array}{lllllll}1 & 4 & 0 & 0 & 0 & 0 & 5 \\ 2 & 0 & 0 & 1 & 0 & 1 & 4\end{array}$

20

20

$13 \quad 0$

30

30

50

$55 \quad 0$

60

$1 \quad 0$

$0 \quad 0$

15
$0 \quad 0$
0

0

0

0

0

0

0

2

0

0

1

0

0

0

1

0

0

0

0

0

0

0

0

0

0

1

0

0

0

0

2

0

1

0

0

2

13

3

5

93

55

8

1 
Appendix - Table A1

\begin{tabular}{|c|c|c|c|c|c|c|c|}
\hline Family, morphospecies & Org & $\mathrm{ABO}$ & Conv-d & IPM-d & IPM-i & Conv & Total \\
\hline Eulop_16 & 0 & 1 & 1 & 0 & 0 & 0 & 2 \\
\hline Eulop_17 & 0 & 1 & 3 & 0 & 1 & 0 & 5 \\
\hline Eulop_18 & 0 & 0 & 0 & 0 & 0 & 1 & 1 \\
\hline Eulop_19 & 5 & 0 & 0 & 0 & 0 & 19 & 24 \\
\hline Eulop_20 & 1 & 0 & 0 & 0 & 0 & 0 & 1 \\
\hline Eulop_21 & 1 & 0 & 0 & 0 & 0 & 1 & 2 \\
\hline Eulop_22 & 2 & 0 & 0 & 0 & 1 & 0 & 3 \\
\hline Eulop_23 & 1 & 0 & 0 & 0 & 0 & 0 & 1 \\
\hline Eulop_24 & 1 & 0 & 0 & 0 & 0 & 0 & 1 \\
\hline Eulop_25 & 1 & 0 & 0 & 0 & 0 & 0 & 1 \\
\hline Eulop_26 & 1 & 0 & 0 & 0 & 0 & 0 & 1 \\
\hline Eulop_27 & 0 & 0 & 0 & 1 & 0 & 0 & 1 \\
\hline Eulop_28 & 0 & 0 & 0 & 1 & 1 & 0 & 2 \\
\hline Eulop_29 & 0 & 0 & 0 & 0 & 0 & 1 & 1 \\
\hline Eulop_30 & 0 & 0 & 0 & 0 & 0 & 1 & 1 \\
\hline Eulop_31 & 0 & 0 & 0 & 0 & 0 & 1 & 1 \\
\hline Eulop_32 & 0 & 0 & 1 & 0 & 0 & 0 & 1 \\
\hline Eulop_33 & 0 & 0 & 1 & 0 & 0 & 0 & 1 \\
\hline Eulop_34 & 0 & 1 & 0 & 0 & 0 & 0 & 1 \\
\hline Eulop_35 & 0 & 2 & 0 & 0 & 0 & 0 & 2 \\
\hline Eulop_36 & 1 & 0 & 0 & 0 & 0 & 0 & 1 \\
\hline Eulop_37 & 1 & 0 & 0 & 0 & 0 & 0 & 1 \\
\hline Eulop_38 & 1 & 0 & 0 & 0 & 0 & 0 & 1 \\
\hline \multicolumn{8}{|l|}{ Eurytomidae } \\
\hline Eury_01 & 0 & 0 & 1 & 0 & 0 & 0 & 1 \\
\hline Eury_02 & 0 & 0 & 2 & 0 & 0 & 0 & 2 \\
\hline \multicolumn{8}{|l|}{ Figitidae } \\
\hline Fig_01 & 0 & 1 & 1 & 1 & 0 & 0 & 3 \\
\hline Fig_02 & 1 & 0 & 1 & 1 & 1 & 0 & 4 \\
\hline Fig_03 & 2 & 2 & 0 & 1 & 0 & 2 & 7 \\
\hline Fig_04 & 0 & 1 & 0 & 0 & 0 & 0 & 1 \\
\hline \multicolumn{8}{|l|}{ Ichneumonidae } \\
\hline Ich_01 & 0 & 0 & 0 & 0 & 1 & 0 & 1 \\
\hline Ich_02 & 1 & 1 & 0 & 0 & 0 & 3 & 5 \\
\hline Ich_03 & 0 & 0 & 0 & 1 & 0 & 0 & 1 \\
\hline Ich_04 & 1 & 0 & 0 & 0 & 1 & 1 & 3 \\
\hline Ich_05 & 1 & 0 & 0 & 0 & 0 & 0 & 1 \\
\hline Ich_06 & 0 & 0 & 0 & 0 & 1 & 0 & 1 \\
\hline Ich_07 & 0 & 0 & 0 & 0 & 1 & 0 & 1 \\
\hline Ich_08 & 0 & 0 & 0 & 0 & 1 & 1 & 2 \\
\hline Ich_09 & 0 & 1 & 0 & 0 & 0 & 0 & 1 \\
\hline
\end{tabular}


Appendix - Table A1

\begin{tabular}{lrrrrrrr}
\hline Family, morphospecies & Org & ABO & Conv-d & IPM-d & IPM-i & Conv & Total \\
\hline Ich_10 & 0 & 1 & 0 & 0 & 0 & 0 & 1 \\
Ich_11 & 1 & 0 & 0 & 0 & 0 & 0 & 1 \\
Megaspilidae & & & & & & & \\
Meg_01 & 0 & 0 & 0 & 1 & 0 & 0 & 1 \\
Meg_02 & 0 & 2 & 0 & 0 & 0 & 0 & 2 \\
Mymaridae & & & & & & & \\
Mym_01 & 0 & 1 & 1 & 0 & 0 & 0 & 2 \\
Mym_02 & 0 & 1 & 0 & 0 & 0 & 0 & 1 \\
Mym_03 & 0 & 0 & 2 & 0 & 0 & 0 & 2 \\
Mym_04 & 3 & 0 & 0 & 1 & 0 & 0 & 4 \\
Mym_05 & 1 & 0 & 0 & 0 & 0 & 0 & 1 \\
Mym_06 & 1 & 0 & 0 & 0 & 0 & 0 & 1 \\
Mym_07 & 1 & 0 & 0 & 0 & 0 & 0 & 1 \\
Mym_08 & 0 & 0 & 0 & 0 & 0 & 1 & 1 \\
Mym_09 & 0 & 0 & 0 & 0 & 0 & 1 & 1 \\
Mym_10 & 0 & 0 & 0 & 0 & 0 & 1 & 1 \\
Mym_11 & 0 & 0 & 1 & 0 & 0 & 0 & 1 \\
Mym_12 & 0 & 1 & 0 & 0 & 0 & 0 & 1
\end{tabular}

Platygastridae

\begin{tabular}{|c|c|c|c|c|c|c|c|}
\hline Plat_01 & 1 & 1 & 2 & 1 & 0 & 0 & 5 \\
\hline Plat_02 & 1 & 5 & 6 & 3 & 1 & 0 & 16 \\
\hline Plat_03 & 0 & 2 & 1 & 1 & 0 & 0 & 4 \\
\hline Plat_05 & 0 & 0 & 0 & 1 & 0 & 1 & 2 \\
\hline Plat_06 & 2 & 0 & 0 & 0 & 0 & 0 & 2 \\
\hline Plat_07 & 0 & 1 & 0 & 0 & 0 & 0 & 1 \\
\hline Plat_09 & 0 & 4 & 2 & 0 & 0 & 2 & 8 \\
\hline Plat_10 & 0 & 1 & 1 & 0 & 0 & 0 & 2 \\
\hline Plat_11 & 0 & 1 & 3 & 1 & 0 & 0 & 5 \\
\hline Plat_12 & 1 & 1 & 2 & 0 & 0 & 1 & 5 \\
\hline Plat_13 & 0 & 0 & 1 & 1 & 0 & 2 & 4 \\
\hline Plat_14 & 1 & 0 & 0 & 3 & 0 & 0 & 4 \\
\hline Plat_15 & 1 & 0 & 0 & 0 & 0 & 0 & 1 \\
\hline Plat_16 & 1 & 0 & 0 & 0 & 0 & 0 & 1 \\
\hline Plat_17 & 1 & 0 & 0 & 0 & 0 & 0 & 1 \\
\hline Plat_18 & 0 & 0 & 0 & 0 & 1 & 1 & 2 \\
\hline Plat_19 & 0 & 0 & 1 & 1 & 0 & 0 & 2 \\
\hline Plat_20 & 0 & 0 & 0 & 1 & 0 & 0 & 1 \\
\hline Plat_21 & 0 & 0 & 0 & 0 & 1 & 0 & 1 \\
\hline Plat_22 & 0 & 0 & 0 & 0 & 0 & 1 & 1 \\
\hline Plat_23 & 0 & 0 & 0 & 0 & 0 & 1 & 1 \\
\hline Plat_24 & 0 & 1 & 0 & 0 & 0 & 0 & 1 \\
\hline
\end{tabular}


Appendix - Table A1

\begin{tabular}{lrrrrrrr}
\hline Family,morphospecies & Org & ABO & Conv-d & IPM-d & IPM-i & Conv & Total \\
\hline Plat_25 & 1 & 0 & 0 & 0 & 0 & 0 & 1 \\
Pteromalidae & & & & & & & \\
Ptero_01 & 0 & 2 & 0 & 0 & 0 & 0 & 2 \\
Ptero_02 & 0 & 0 & 1 & 1 & 1 & 0 & 3 \\
Ptero_03 & 1 & 0 & 0 & 0 & 0 & 0 & 1 \\
Ptero_04 & 3 & 0 & 0 & 0 & 0 & 0 & 3 \\
Ptero_05 & 1 & 0 & 1 & 1 & 0 & 0 & 3 \\
Ptero_06 & 10 & 0 & 0 & 0 & 0 & 0 & 10 \\
Ptero_07 & 4 & 0 & 0 & 0 & 0 & 0 & 4 \\
Ptero_08 & 1 & 0 & 0 & 0 & 0 & 0 & 1 \\
Ptero_10 & 1 & 0 & 0 & 0 & 0 & 0 & 1 \\
Ptero_11 & 2 & 0 & 0 & 0 & 0 & 2 & 4 \\
Ptero_12 & 1 & 0 & 0 & 0 & 0 & 0 & 1 \\
Ptero_14 & 0 & 10 & 0 & 0 & 0 & 0 & 10 \\
Ptero_16 & 0 & 1 & 0 & 0 & 0 & 0 & 1 \\
Ptero_17 & 2 & 0 & 0 & 0 & 0 & 0 & 2 \\
Ptero_18 & 1 & 0 & 0 & 0 & 0 & 0 & 1 \\
Ptero_19 & 1 & 0 & 0 & 0 & 0 & 0 & 1 \\
Ptero_20 & 2 & 0 & 0 & 0 & 0 & 0 & 2 \\
Ptero_21 & 0 & 0 & 0 & 0 & 0 & 1 & 1 \\
Ptero_22 & 0 & 0 & 0 & 0 & 0 & 1 & 1 \\
Ptero_23 & 2 & 0 & 0 & 0 & 0 & 0 & 2 \\
Ptero_24 & 1 & 0 & 0 & 0 & 0 & 0 & 1
\end{tabular}

Sierolomorphidae

$\begin{array}{llllllll}\text { Sierolomorpha } & 1 & 0 & 0 & 0 & 0 & 0 & 1\end{array}$
canadensis

Torymidae

\begin{tabular}{lrrrrrrr} 
Tory_01 & 0 & 0 & 1 & 0 & 0 & 0 & 1 \\
\hline Individuals, identified & 202 & 198 & 69 & 118 & 37 & 187 & 811 \\
\hline $\begin{array}{l}\text { Unidentifiable (used for abundance only) } \\
\text { May samples }\end{array}$ & 28 & 3 & 7 & 19 & 1 & 16 & 74 \\
ChalX (Jun-Aug) & 0 & 1 & 2 & 2 & 0 & 2 & 7 \\
\hline Total individuals & 230 & 202 & 78 & 139 & 38 & 205 & 892 \\
Total species & 71 & 45 & 35 & 34 & 33 & 35 & 169 \\
Total families & 11 & 13 & 11 & 12 & 10 & 8 & 16 \\
\hline
\end{tabular}


TABLE A2. Post-hoc pairwise comparisons from repeated measures ANOVA comparing mean wasp abundance across orchards within each month (month $\mathrm{x}$ orchard). Abundance was natural $\log$ transformed. A Bonferroni correction for multiple comparisons was used within each month. Significant differences are indicated by an asterisk.

\begin{tabular}{|c|c|c|c|c|c|c|c|c|}
\hline \multirow[b]{2}{*}{ Month } & \multirow{2}{*}{$\begin{array}{c}\text { (I) } \\
\text { Orchard }\end{array}$} & \multirow{2}{*}{$\begin{array}{c}(\mathrm{J}) \\
\text { Orchard }\end{array}$} & \multirow{2}{*}{$\begin{array}{l}\text { Mean } \\
\text { Difference } \\
(\mathrm{I}-\mathrm{J})\end{array}$} & \multirow{2}{*}{$\begin{array}{l}\text { Std. } \\
\text { Error }\end{array}$} & \multirow[b]{2}{*}{$\mathrm{df}$} & \multirow[b]{2}{*}{$\mathrm{p}$} & \multicolumn{2}{|c|}{$\begin{array}{l}95 \% \text { Confidence Interval for } \\
\text { Difference }\end{array}$} \\
\hline & & & & & & & Lower Bound & Upper Bound \\
\hline \multirow[t]{30}{*}{ May } & Org & $\mathrm{ABO}$ & $.979^{*}$ & .237 & 216 & $.001 *$ & .276 & 1.683 \\
\hline & & IPM-d & .183 & .237 & 216 & 1.000 & -.521 & .886 \\
\hline & & IPM-i & $1.089^{*}$ & .237 & 216 & $>.001 *$ & .386 & 1.793 \\
\hline & & Conv-d & $.760^{*}$ & .237 & 216 & $.023^{*}$ & .056 & 1.463 \\
\hline & & Conv & .413 & .237 & 216 & 1.000 & -.291 & 1.117 \\
\hline & $\mathrm{ABO}$ & Org & $-.979^{*}$ & .237 & 216 & $.001 *$ & -1.683 & -.276 \\
\hline & & IPM-d & $-.797^{*}$ & .237 & 216 & $.014^{*}$ & -1.500 & -.093 \\
\hline & & IPM-i & .110 & .237 & 216 & 1.000 & -.594 & .814 \\
\hline & & Conv-d & -.220 & .237 & 216 & 1.000 & -.923 & .484 \\
\hline & & Conv & -.566 & .237 & 216 & .266 & -1.270 & .137 \\
\hline & IPM-d & Org & -.183 & .237 & 216 & 1.000 & -.886 & .521 \\
\hline & & $\mathrm{ABO}$ & $.797^{*}$ & .237 & 216 & $.014^{*}$ & .093 & 1.500 \\
\hline & & IPM-i & $.906^{*}$ & .237 & 216 & $.003 *$ & .203 & 1.610 \\
\hline & & Conv-d & .577 & .237 & 216 & .237 & -.127 & 1.280 \\
\hline & & Conv & .230 & .237 & 216 & 1.000 & -.473 & .934 \\
\hline & IPM-i & Org & $-1.089^{*}$ & .237 & 216 & $>.001^{*}$ & -1.793 & -.386 \\
\hline & & $\mathrm{ABO}$ & -.110 & .237 & 216 & 1.000 & -.814 & .594 \\
\hline & & IPM-d & $-.906^{*}$ & .237 & 216 & $.003 *$ & -1.610 & -.203 \\
\hline & & Conv-d & -.330 & .237 & 216 & 1.000 & -1.033 & .374 \\
\hline & & Conv & -.676 & .237 & 216 & .071 & -1.380 & .027 \\
\hline & Conv-d & Org & $-.760^{*}$ & .237 & 216 & $.023^{*}$ & -1.463 & -.056 \\
\hline & & $\mathrm{ABO}$ & .220 & .237 & 216 & 1.000 & -.484 & .923 \\
\hline & & IPM-d & -.577 & .237 & 216 & .237 & -1.280 & .127 \\
\hline & & IPM-i & .330 & .237 & 216 & 1.000 & -.374 & 1.033 \\
\hline & & Conv & -.347 & .237 & 216 & 1.000 & -1.050 & .357 \\
\hline & Conv & Org & -.413 & .237 & 216 & 1.000 & -1.117 & .291 \\
\hline & & $\mathrm{ABO}$ & .566 & .237 & 216 & .266 & -.137 & 1.270 \\
\hline & & IPM-d & -.230 & .237 & 216 & 1.000 & -.934 & .473 \\
\hline & & IPM-i & .676 & .237 & 216 & .071 & -.027 & 1.380 \\
\hline & & Conv-d & .347 & .237 & 216 & 1.000 & -.357 & 1.050 \\
\hline June & Org & $\mathrm{ABO}$ & .639 & .237 & 216 & .114 & -.065 & 1.342 \\
\hline
\end{tabular}




\begin{tabular}{|c|c|c|c|c|c|c|c|c|}
\hline \multirow[b]{2}{*}{ Month } & \multirow{2}{*}{$\begin{array}{c}\text { (I) } \\
\text { Orchard }\end{array}$} & \multirow{2}{*}{$\begin{array}{c}(\mathrm{J}) \\
\text { Orchard }\end{array}$} & \multirow{2}{*}{$\begin{array}{c}\text { Mean } \\
\text { Difference } \\
(\mathrm{I}-\mathrm{J})\end{array}$} & \multirow{2}{*}{$\begin{array}{l}\text { Std. } \\
\text { Error }\end{array}$} & \multirow[b]{2}{*}{$\mathrm{df}$} & \multirow[b]{2}{*}{$\mathrm{p}$} & \multicolumn{2}{|c|}{$\begin{array}{l}\text { 95\% Confidence Interval for } \\
\text { Difference }\end{array}$} \\
\hline & & & & & & & Lower Bound & Upper Bound \\
\hline \multirow[t]{29}{*}{ June } & Org & IPM-d & $1.091^{*}$ & .237 & 216 & $>.001 *$ & .387 & 1.795 \\
\hline & & IPM-i & $1.531^{*}$ & .237 & 216 & $>.001 *$ & .827 & 2.234 \\
\hline & & Conv-d & $1.388^{*}$ & .237 & 216 & $>.001 *$ & .684 & 2.091 \\
\hline & & Conv & $1.958^{*}$ & .237 & 216 & $>.001 *$ & 1.255 & 2.662 \\
\hline & $\mathrm{ABO}$ & Org & -.639 & .237 & 216 & .114 & -1.342 & .065 \\
\hline & & IPM-d & .452 & .237 & 216 & .865 & -.251 & 1.156 \\
\hline & & IPM-i & $.892^{*}$ & .237 & 216 & $.003 *$ & .188 & 1.595 \\
\hline & & Conv-d & $.749^{*}$ & .237 & 216 & $.027 *$ & .045 & 1.453 \\
\hline & & Conv & $1.319^{*}$ & .237 & 216 & $>.001 *$ & .616 & 2.023 \\
\hline & IPM-d & Org & $-1.091^{*}$ & .237 & 216 & $>.001 *$ & -1.795 & -.387 \\
\hline & & $\mathrm{ABO}$ & -.452 & .237 & 216 & .865 & -1.156 & .251 \\
\hline & & IPM-i & .439 & .237 & 216 & .977 & -.264 & 1.143 \\
\hline & & Conv-d & .297 & .237 & 216 & 1.000 & -.407 & 1.000 \\
\hline & & Conv & $.867^{*}$ & .237 & 216 & $.005^{*}$ & .163 & 1.571 \\
\hline & IPM-i & Org & $-1.531^{*}$ & .237 & 216 & $>.001 *$ & -2.234 & -.827 \\
\hline & & $\mathrm{ABO}$ & $-.892^{*}$ & .237 & 216 & $.003 *$ & -1.595 & -.188 \\
\hline & & IPM-d & -.439 & .237 & 216 & .977 & -1.143 & .264 \\
\hline & & Conv-d & -.143 & .237 & 216 & 1.000 & -.846 & .561 \\
\hline & & Conv & .428 & .237 & 216 & 1.000 & -.276 & 1.131 \\
\hline & Conv-d & Org & $-1.388^{*}$ & .237 & 216 & $>.001 *$ & -2.091 & -.684 \\
\hline & & $\mathrm{ABO}$ & $-.749^{*}$ & .237 & 216 & $.027 *$ & -1.453 & -.045 \\
\hline & & IPM-d & -.297 & .237 & 216 & 1.000 & -1.000 & .407 \\
\hline & & IPM-i & .143 & .237 & 216 & 1.000 & -.561 & .846 \\
\hline & & Conv & .570 & .237 & 216 & .255 & -.133 & 1.274 \\
\hline & Conv & Org & $-1.958^{*}$ & .237 & 216 & $>.001 *$ & -2.662 & -1.255 \\
\hline & & $\mathrm{ABO}$ & $-1.319^{*}$ & .237 & 216 & $>.001 *$ & -2.023 & -.616 \\
\hline & & IPM-d & $-.867^{*}$ & .237 & 216 & $.005^{*}$ & -1.571 & -.163 \\
\hline & & IPM-i & -.428 & .237 & 216 & 1.000 & -1.131 & .276 \\
\hline & & Conv-d & -.570 & .237 & 216 & .255 & -1.274 & .133 \\
\hline \multirow[t]{7}{*}{ July } & Org & $\mathrm{ABO}$ & .423 & .237 & 216 & 1.000 & -.281 & 1.127 \\
\hline & & IPM-d & .474 & .237 & 216 & .700 & -.229 & 1.178 \\
\hline & & IPM-i & $1.457^{*}$ & .237 & 216 & $>.001 *$ & .753 & 2.160 \\
\hline & & Conv-d & $1.544^{*}$ & .237 & 216 & $>.001 *$ & .841 & 2.248 \\
\hline & & Conv & $1.526^{*}$ & .237 & 216 & $>.001 *$ & .822 & 2.230 \\
\hline & $\mathrm{ABO}$ & Org & -.423 & .237 & 216 & 1.000 & -1.127 & .281 \\
\hline & & IPM-d & .051 & .237 & 216 & 1.000 & -.652 & .755 \\
\hline
\end{tabular}




\begin{tabular}{|c|c|c|c|c|c|c|c|c|}
\hline \multirow[b]{2}{*}{ Month } & \multirow{2}{*}{$\begin{array}{c}\text { (I) } \\
\text { Orchard }\end{array}$} & \multirow{2}{*}{$\begin{array}{c}(\mathrm{J}) \\
\text { Orchard }\end{array}$} & \multirow{2}{*}{$\begin{array}{c}\text { Mean } \\
\text { Difference } \\
(\mathrm{I}-\mathrm{J})\end{array}$} & \multirow{2}{*}{$\begin{array}{l}\text { Std. } \\
\text { Error }\end{array}$} & \multirow[b]{2}{*}{$\mathrm{df}$} & \multirow[b]{2}{*}{$\mathrm{p}$} & \multicolumn{2}{|c|}{$\begin{array}{c}\text { 95\% Confidence Interval for } \\
\text { Difference }\end{array}$} \\
\hline & & & & & & & Lower Bound & Upper Bound \\
\hline \multirow[t]{23}{*}{ July } & $\mathrm{ABO}$ & IPM-i & $1.034^{*}$ & .237 & 216 & $>.001 *$ & .330 & 1.737 \\
\hline & & Conv-d & $1.121^{*}$ & .237 & 216 & $>.001 *$ & .418 & 1.825 \\
\hline & & Conv & $1.103^{*}$ & .237 & 216 & $>.001 *$ & .399 & 1.807 \\
\hline & IPM-d & Org & -.474 & .237 & 216 & .700 & -1.178 & .229 \\
\hline & & $\mathrm{ABO}$ & -.051 & .237 & 216 & 1.000 & -.755 & .652 \\
\hline & & IPM-i & $.982^{*}$ & .237 & 216 & $.001 *$ & .279 & 1.686 \\
\hline & & Conv-d & $1.070^{*}$ & .237 & 216 & $>.001 *$ & .366 & 1.774 \\
\hline & & Conv & $1.052^{*}$ & .237 & 216 & $>.001 *$ & .348 & 1.755 \\
\hline & IPM-i & Org & $-1.457^{*}$ & .237 & 216 & $>.001 *$ & -2.160 & -.753 \\
\hline & & $\mathrm{ABO}$ & $-1.034^{*}$ & .237 & 216 & $>.001 *$ & -1.737 & -.330 \\
\hline & & IPM-d & $-.982^{*}$ & .237 & 216 & $.001 *$ & -1.686 & -.279 \\
\hline & & Conv-d & .088 & .237 & 216 & 1.000 & -.616 & .791 \\
\hline & & Conv & .069 & .237 & 216 & 1.000 & -.634 & .773 \\
\hline & Conv-d & Org & $-1.544^{*}$ & .237 & 216 & $>.001 *$ & -2.248 & -.841 \\
\hline & & $\mathrm{ABO}$ & $-1.121^{*}$ & .237 & 216 & $>.001 *$ & -1.825 & -.418 \\
\hline & & IPM-d & $-1.070^{*}$ & .237 & 216 & $>.001 *$ & -1.774 & -.366 \\
\hline & & IPM-i & -.088 & .237 & 216 & 1.000 & -.791 & .616 \\
\hline & & Conv & -.018 & .237 & 216 & 1.000 & -.722 & .685 \\
\hline & Conv & Org & $-1.526^{*}$ & .237 & 216 & $>.001 *$ & -2.230 & -.822 \\
\hline & & $\mathrm{ABO}$ & $-1.103^{*}$ & .237 & 216 & $>.001 *$ & -1.807 & -.399 \\
\hline & & IPM-d & $-1.052^{*}$ & .237 & 216 & $>.001 *$ & -1.755 & -.348 \\
\hline & & IPM-i & -.069 & .237 & 216 & 1.000 & -.773 & .634 \\
\hline & & Conv-d & .018 & .237 & 216 & 1.000 & -.685 & .722 \\
\hline \multirow[t]{12}{*}{ Aug } & Org & $\mathrm{ABO}$ & $-.704^{*}$ & .237 & 216 & .050 & -1.408 & -.001 \\
\hline & & IPM-d & -.024 & .237 & 216 & 1.000 & -.727 & .680 \\
\hline & & IPM-i & $.878^{*}$ & .237 & 216 & $.004 *$ & .174 & 1.581 \\
\hline & & Conv-d & .113 & .237 & 216 & 1.000 & -.591 & .817 \\
\hline & & Conv & $-1.240^{*}$ & .237 & 216 & $>.001^{*}$ & -1.944 & -.536 \\
\hline & $\mathrm{ABO}$ & Org & $.704^{*}$ & .237 & 216 & .050 & .001 & 1.408 \\
\hline & & IPM-d & .681 & .237 & 216 & .068 & -.023 & 1.384 \\
\hline & & IPM-i & $1.582^{*}$ & .237 & 216 & $>.001 *$ & .878 & 2.286 \\
\hline & & Conv-d & $.817^{*}$ & .237 & 216 & $.010^{*}$ & .114 & 1.521 \\
\hline & & Conv & -.536 & .237 & 216 & .372 & -1.240 & .168 \\
\hline & IPM-d & Org & .024 & .237 & 216 & 1.000 & -.680 & .727 \\
\hline & & $\mathrm{ABO}$ & -.681 & .237 & 216 & .068 & -1.384 & .023 \\
\hline
\end{tabular}


Appendix - Table A2

\begin{tabular}{|c|c|c|c|c|c|c|c|c|}
\hline \multirow[b]{2}{*}{ Month } & \multirow{2}{*}{$\begin{array}{c}\text { (I) } \\
\text { Orchard }\end{array}$} & \multirow{2}{*}{$\begin{array}{c}(\mathrm{J}) \\
\text { Orchard }\end{array}$} & \multirow{2}{*}{$\begin{array}{c}\text { Mean } \\
\text { Difference } \\
(\mathrm{I}-\mathrm{J})\end{array}$} & \multirow{2}{*}{$\begin{array}{l}\text { Std. } \\
\text { Error }\end{array}$} & \multirow[b]{2}{*}{$\mathrm{df}$} & \multirow[b]{2}{*}{$\mathrm{p}$} & \multicolumn{2}{|c|}{$\begin{array}{c}95 \% \text { Confidence Interval for } \\
\text { Difference }\end{array}$} \\
\hline & & & & & & & Lower Bound & Upper Bound \\
\hline \multirow[t]{18}{*}{ Aug } & IPM-d & IPM-i & $.901^{*}$ & .237 & 216 & $.003 *$ & .198 & 1.605 \\
\hline & & Conv-d & .137 & .237 & 216 & 1.000 & -.567 & .840 \\
\hline & & Conv & $-1.216^{*}$ & .237 & 216 & $>.001 *$ & -1.920 & -.513 \\
\hline & IPM-i & Org & $-.878^{*}$ & .237 & 216 & $.004 *$ & -1.581 & -.174 \\
\hline & & $\mathrm{ABO}$ & $-1.582^{*}$ & .237 & 216 & $>.001 *$ & -2.286 & -.878 \\
\hline & & IPM-d & $-.901^{*}$ & .237 & 216 & $.003 *$ & -1.605 & -.198 \\
\hline & & Conv-d & $-.765^{*}$ & .237 & 216 & .022 & -1.468 & -.061 \\
\hline & & Conv & $-2.118^{*}$ & .237 & 216 & .000 & -2.821 & -1.414 \\
\hline & Conv-d & Org & -.113 & .237 & 216 & 1.000 & -.817 & .591 \\
\hline & & $\mathrm{ABO}$ & $-.817^{*}$ & .237 & 216 & .010 & -1.521 & -.114 \\
\hline & & IPM-d & -.137 & .237 & 216 & 1.000 & -.840 & .567 \\
\hline & & IPM-i & $.765^{*}$ & .237 & 216 & .022 & .061 & 1.468 \\
\hline & & Conv & $-1.353^{*}$ & .237 & 216 & .000 & -2.057 & -.650 \\
\hline & Conv & Org & $1.240^{*}$ & .237 & 216 & .000 & .536 & 1.944 \\
\hline & & $\mathrm{ABO}$ & .536 & .237 & 216 & .372 & -.168 & 1.240 \\
\hline & & IPM-d & $1.216^{*}$ & .237 & 216 & .000 & .513 & 1.920 \\
\hline & & IPM-i & $2.118^{*}$ & .237 & 216 & .000 & 1.414 & 2.821 \\
\hline & & Conv-d & $1.353^{*}$ & .237 & 216 & .000 & .650 & 2.057 \\
\hline
\end{tabular}




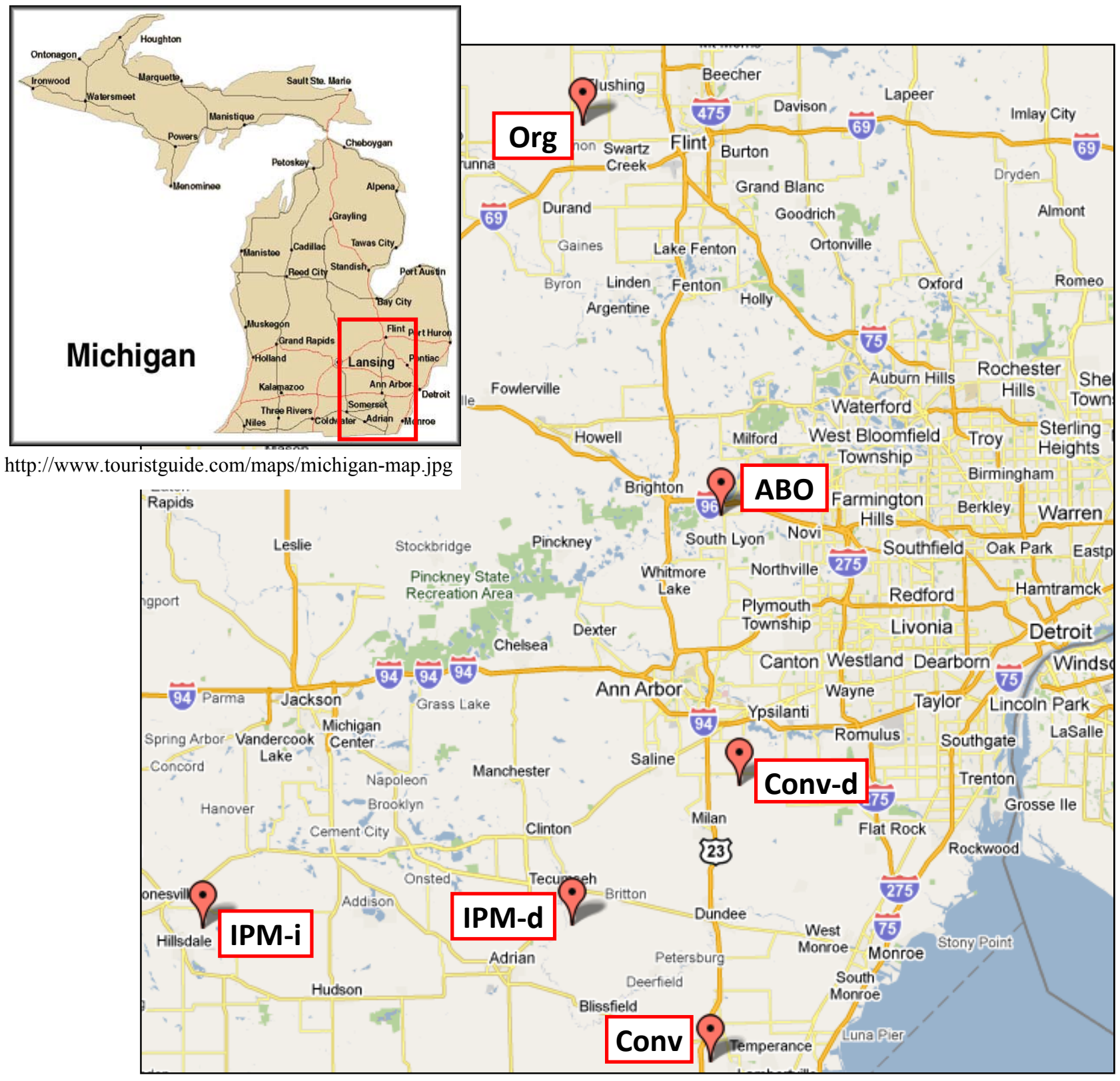

http://maps.google.com/maps/ms?ie=UTF8\&hl=en\&msa=0\&msid=100031109582419974394.000467ca70d73ad592777\&z=9

FIG. A1. Map of six study orchards in southeastern Michigan, USA. 